\title{
SPECIFIC HEAT AND HEAT OF FUSION OF ICE
}

\author{
By H. C. Dickinson and N. S. Osborne
}

\section{CONTENTS}

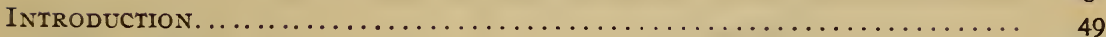

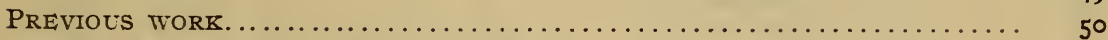

DESCRIPTION OF CALORIMETRIC METHOD......................... 52

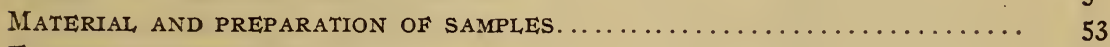

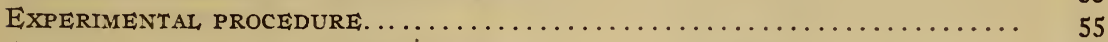

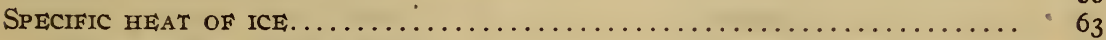

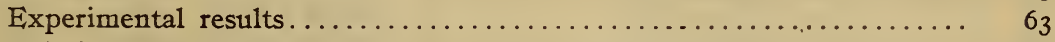

Relation between apparent specific heat of ice and dissolved impurities... 69

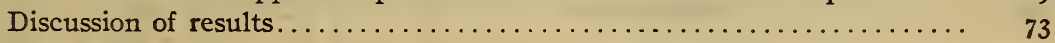

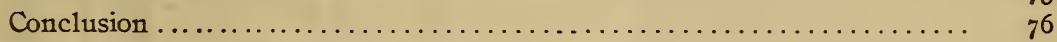

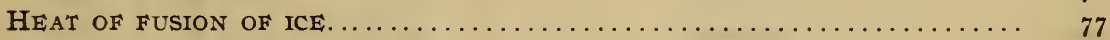

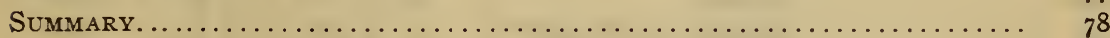

TABLE OF TOTAL HEAT OF ICE AND WATER...................... 79

\section{INTRODUCTION}

The present investigation is one of a series undertaken, at the request of the refrigeration industries, for the determination of constants which are of fundamental importance in the design and operation of refrigeration machinery.

A determination made at the Bureau ${ }^{1}$ of the heat of fusion of ice was published in I9I3. In this publication is given a review of previous work on this subject. As stated there the results presented are subject to a slight uncertainty on account of the lack of adequate knowledge of the specific heat of ice near the melting point. For this reason and also on account of the direct technical significance of the specific heat of ice, it has been made the subject of the work here presented.

1 Dickinson, Harper, and Osborne, this Bulletin, 10, p. 235, 1913, Scientific Paper No. 209. 


\section{PREVIOUS WORK}

A review of previous determinations of the heat of fusion of ice is given in the publication cited above.

The results of previous experimental determinations of the specific heat of ice are summarized in Table $\mathrm{I}$.

TABLE 1

Specific Heat of Ice-Results of Previous Observers

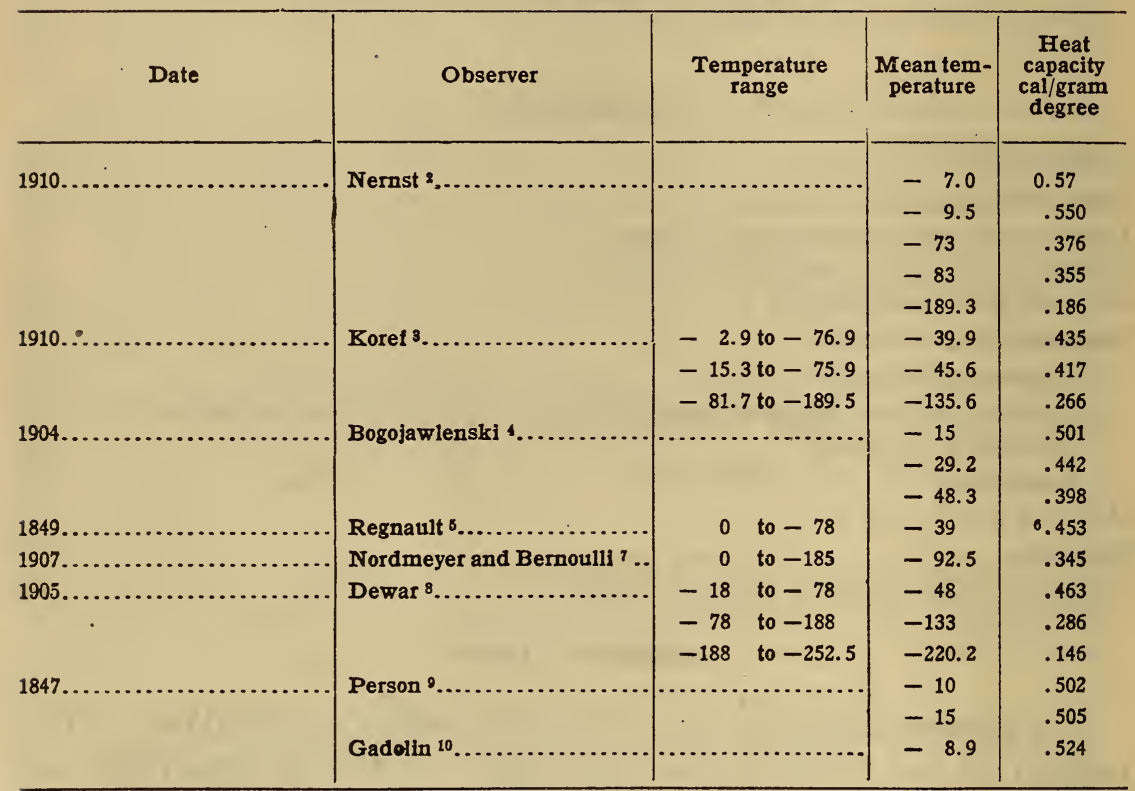

2 Nernst, K. Ak. d. Wiss. Sitzb., I910, p. 262.

Koref, K. Ak. d. Wiss. Sitzb., I9ro, p. 253.

1 Bogojawlenski, Schr. der Dorpater Naturf. Ges., 13, p. I.

6 Regnault, Ann. d. Chim. (3), 26, p. 26r, 1849.

- Value given by Nernst (loc. cit.), recalculated from original on basis of specific heat of lead.

'Nordmeyer and Bernoulli, Verh. d. Deutch. Phys. Ges., 9, p. 175; 1907.

8 Dewar,. Proc. Roy. Soc. Lond., 76, p. 330; I905.

- Person, Ann. Chim. et Phys. (3), 21, p. 295; 1847.

10 Review by Ångstrom, Ann. d. Phys., 90, p. 509; 1853. Original, Nov. Act. Reg. Soc. Upsala, 5.

Nernst and his associates have deduced an empirical equation expressing their results on the specific heat of ice relative to its temperature. The graphical representation of this equation, together with the observed results of different experimenters, is shown in Fig. I. The mean temperatures of the determinations 


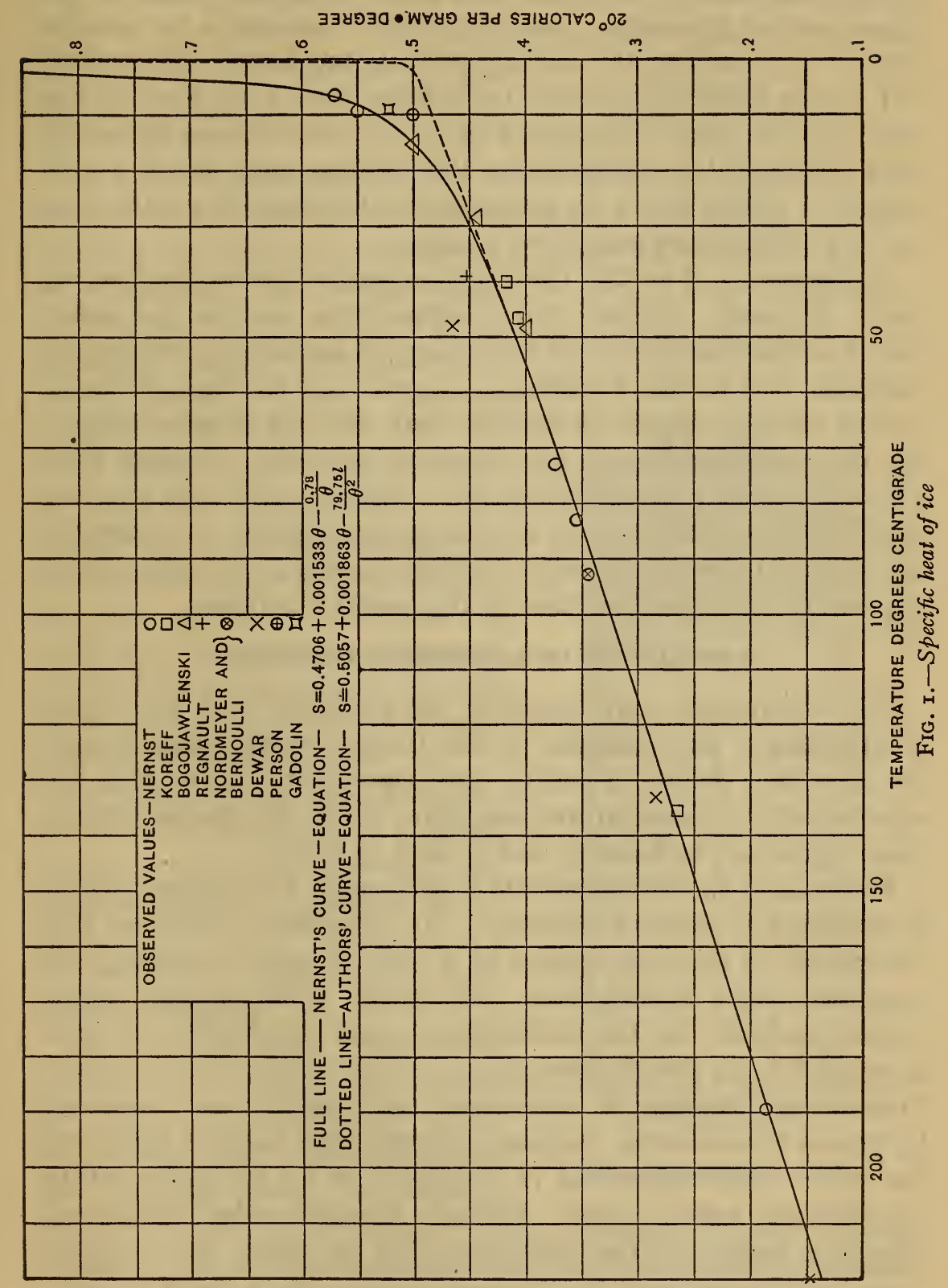


are all below $-7^{\circ} \mathrm{C}$. From the trend of these results in the upper part of the range a very significant increase in the specific heat on approaching the melting point is suggested. This might not appear remarkable except for the fact that A. W. Smith ${ }^{11}$ has observed that while with impure ice an apparent increase in specific heat is obtained on approaching the melting point, ice of a high degree of purity shows no such abnormal change in specific heat up to a temperature very close to zero.

The presence of certain dissolved impurities lowers the freezing point of water. At any given temperature not too far below zero a certain proportion of an ice sample containing impurity is unfrozen, due to this lowering. A portion of the heat of fusion is thus made to appear as sensible heat, and the observed apparent heat capacity of such ice, especially near zero, is larger than for ice containing no such impurity. Smith's conclusion that the specific heat of pure ice does not change appreciably on approaching zero is therefore plausible, notwithstanding the fact that it appears to be in contradiction to the results of others.

\section{DESCRIPTION OF CALORIMETRIC METHOD}

The experiments here described were planned with the object of attaining a high precision in the thermal measurements upon ice of a high degree of purity, and especially of extending the experiments to temperatures near zero, where the specific heat is more important technically and is most in doubt.

For making the measurements a calorimeter was adopted which is described in detail elsewhere. ${ }^{12}$ An important feature of this calorimeter is the employment of a shell of copper inclosing the specimen under investigation, the copper acting as the calorimetric medium for the transmission and distribution of heat developed in an electric heating coil which is built into the shell. Temperature changes in calorimeter and contents are measured by means of an electric resistance thermometer likewise built into the shell. The calorimeter is suspended in an air space within an inclosing metal jacket. Multiple thermocouples distributed about the surfaces of the calorimeter and the jacket serve to indi-

${ }^{11}$ Smith, Physical Review, 17, p. 193; 1903. 12 Dickinson and Osborne, this Bulletin, 12, p. 23, 1915. 
cate at any instant the difference between the average temperatures of the surfaces. This enables the corrections for thermal leakage between calorimeter and its surroundings to be controlled and measured.

The jacket containing the calorimeter is immersed in a stirred liquid bath which, by means of a refrigerating coil using liquid carbon dioxide, an electric heating coil, and a thermoregulator, is maintained at any temperature between $-55^{\circ} \mathrm{C}$ and $+40^{\circ}$ $\mathrm{C}$ to within a few thousandths of a degree. Using current furnished by a storage battery, the heat supplied to the calorimeter and the contained specimen is developed at a nearly constant rate, which is determined by potentiometer measurements of current and of potential drop.

By this method the heat involved in the temperature changes of the material is measured directly in terms of electrical units, from which it may be reduced to customary heat units by using the proper constants.

The ice specimens were contained in a metal cell which fits inside the calorimeter shell. To promote the rapid equalization of temperature, the cell is
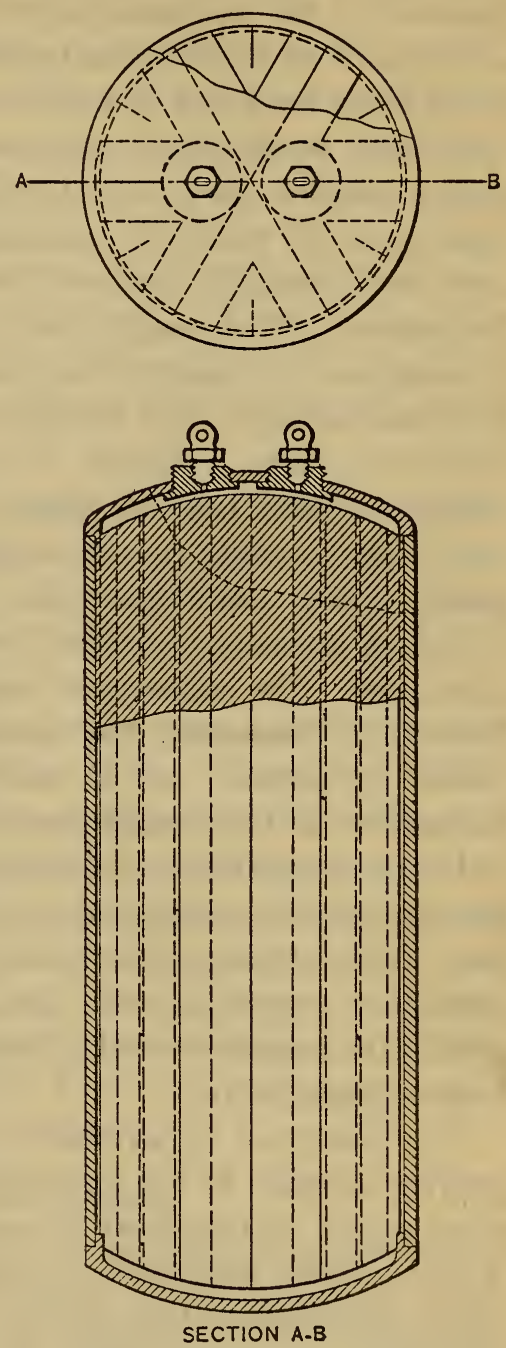

FIG. 2.-Specimen container provided with radial copper vanes attached to the interior surface. The details of construction of the container are shown in Fig. 2. 


\section{MATERIAL AND PREPARATION OF SAMPLES}

Since even small amounts of impurity would cause considerable increase in the apparent heat capacity, due to incipient melting of portions of the ice, the material used for the determinations of the specific heat and of the heat of fusion of ice was prepared with the object of obtaining specimens of ice as pure as possible. The entire interior surface of the ice container was carefully coated with pure tin to avoid contamination of the sample. The water used was specially prepared by repeated distillations to remove impurities. Four samples of ice were prepared. The water used in samples 1,2 , and 3 was poured into the container through a tin-lined funnel. The water was boiled in the container to expel dissolved gases. Sample No. I was frozen in the container directly within the calorimeter by lowering the temperature of the jacket. After the determinations on this sample were completed it was found that this method of freezing had developed sufficient pressure to slightly open the joint at the bottom of the container. The subsequent samples were frozen, beginning at the bottom, by immersing the container into a bath of stirred gasoline cooled to about $-10^{\circ} \mathrm{C}$, and gradually increasing the depth of immersion as the sample froze.

In the preparation of samples 2 and 3 the residual water was poured from the container after freezing sufficient ice for the sample. The interior cellular construction of the container, however, interfered somewhat with the success of this procedure, and the results on samples 2 and 3 indicated only slightly different purity from sample No. $x$.

The results of experiments upon samples $I, 2$, and 3 showed a greater increase in the apparent specific heat on approaching zero thian would be expected in consideration of Smith's experiments, if the samples possessed the degree of purity sought. On the contrary, they showed less increase than the results of other observers. The results upon sample 3 showed somewhat less increase than samples I and 2, which can be accounted for by supposing that sample 3 contained less impurity than the others. To learn, if possible, more in regard to the effect of impurities, an attempt was made to prepare a sample of still greater purity. 
Sample No. 4 was distilled directly into the container, the condensed water touching no surface which was not tinned. In doing this the container was first inverted so that the condensed water would drain out, thus washing the entire interior surface with steam and hot distilled water. After about $800 \mathrm{cc}$ had been thus passed through, the container was placed erect and surrounded with ice. Water was condensed until the container was nearly full, leaving about $700 \mathrm{cc}$ in the distilling flask. Thus, only the middle fraction was retained for the sample. The water used in the distilling flask was specially prepared double distilled water. Before sealing the sample in the container, the contained water was boiled to expel any air which might have been absorbed after condensation.

Measurements of the electrical conductivity of the samples, made after the various determinations were completed, failed to show any considerable difference in the observed conductivities of the different samples. These were all of the order of $3 \times 10^{-6}$ $\mathrm{ohm}^{-1} \mathrm{~cm}^{-1}$.

While the specimens were being frozen the calorimeter was cooled to a temperature slightly below zero. The object of this was to avoid melting any considerable portion of the ice when the container was introduced into the calorimeter. The operation of inserting the specimen into the calorimeter at a temperature of zero was accompanied by the unavoidable condensation of moisture on the calorimeter, as the work was done when the dew point was above zero. To absorb this moisture and to maintain the dryness of the air within, a small dish of calcium chloride was placed at the bottom of the jacket.

\section{EXPERIMENTAL PROCEDURE}

A detailed description of the various operations involved in determination of heat capacity is given in the previous paper referred to above. Briefly stated, the sequence as to manipulations and observations is as follows:

The calorimeter containing the specimen is cooled to the initial temperature of the experiment. The jacket is brought under control of the thermoregulator at the temperature of the calorimeter. The resistance of the built-in platinum thermometer is 
observed to determine the initial temperature ${ }^{13}$ of the calorimeter. Electric current is passed through the heating coil of the calorimeter for a measured interval of time. During this time alternate readings of current ${ }^{14}$ and potential drop are made at equal intervals of time to determine the rate of energy supply to the calorimeter. Meanwhile by hand control of the jacket heating current the temperature of the jacket is kept as nearly as practicable equal to the rising temperature of the calorimeter. The readings of the thermocouples, which are recorded at intervals of 30 seconds throughout the entire experiment, indicate the temperature difference between the calorimeter and jacket, and serve the double purpose of guiding the jacket control and giving the data for determining the thermal leakage. After the interruption of the calorimeter heating current, the jacket is again brought under control of the thermoregulator, and when the calorimeter attains thermal equilibrium the thermometer resistance is again observed to determine the final temperature.

The rate of thermal leakage is determined by a separate experiment, in which, with the calorimeter and jacket at different temperatures, alternate readings are made of the resistance thermometer and of the thermocouple between calorimeter and jacket. An approximate value of the heat capacity of the calorimeter at the time of this supplementary experiment is adequate to enable the computation of the rate to be made.

The mass of the sample is determined from weighings in air against brass weights of the empty container, and of the container with specimen included. The difference between these weighings corrected for air buoyancy gives the mass of the specimen.

An example of the record of a single experiment in determining the specific heat of an ice specimen is given in Fig. 3.

\footnotetext{
18 The temperatures $\theta$ employed in this paper are expressed in degrees of the centigrade scale determined by a resistance thermometer of the Heraeus purest platinum according to the equations

$$
\theta=p t+o\left(\frac{\theta}{100}-1\right) \frac{\theta}{100}, \quad p t=\frac{R_{\theta}-R_{0}}{R_{100}-R_{0}} \mathrm{I00}, \quad \delta=1.48
$$

The value of $\delta$ here taken, viz, 1.48, was obtained by a direct comparison of platinum resistance thermometers of Heraeus purest platinum, in the interval $0^{\circ}$ to $100^{\circ}$ with verre dur thermometers standardized at the Bureau International des Poids et Mesures, and thus serves to reproduce the hydrogen scale of that bureau.

The difference between the scale above defined and the thermodynamic scale as reproduced in the inter$\mathrm{val}-50^{\circ}$ to $+500^{\circ}$ by means of the platinum resistance thermometer standardized at the temperatures of melting ice, steam, and sulphur vapor, consists in the use of $\delta=1.48$ instead of $1.49+$, which would be the value for platinum of the purity here employed when the sulphur boiling point is taken as $444: 6$. At $+50^{\circ}$ the difference between the two scales is less than 9003 , which is within the limits of accuracy of reproduction of the hydrogen scale.

14 All electrical quantities are expressed in terms of the units adopted by the Bureau of Standards, as given in Bureau Circular No. 29, rst ed.
} 
Observers, N.S. O., C. H.M.

\section{CALORIMETER RECORD}

Date, Aug. 6, 1914

Experiment No.s

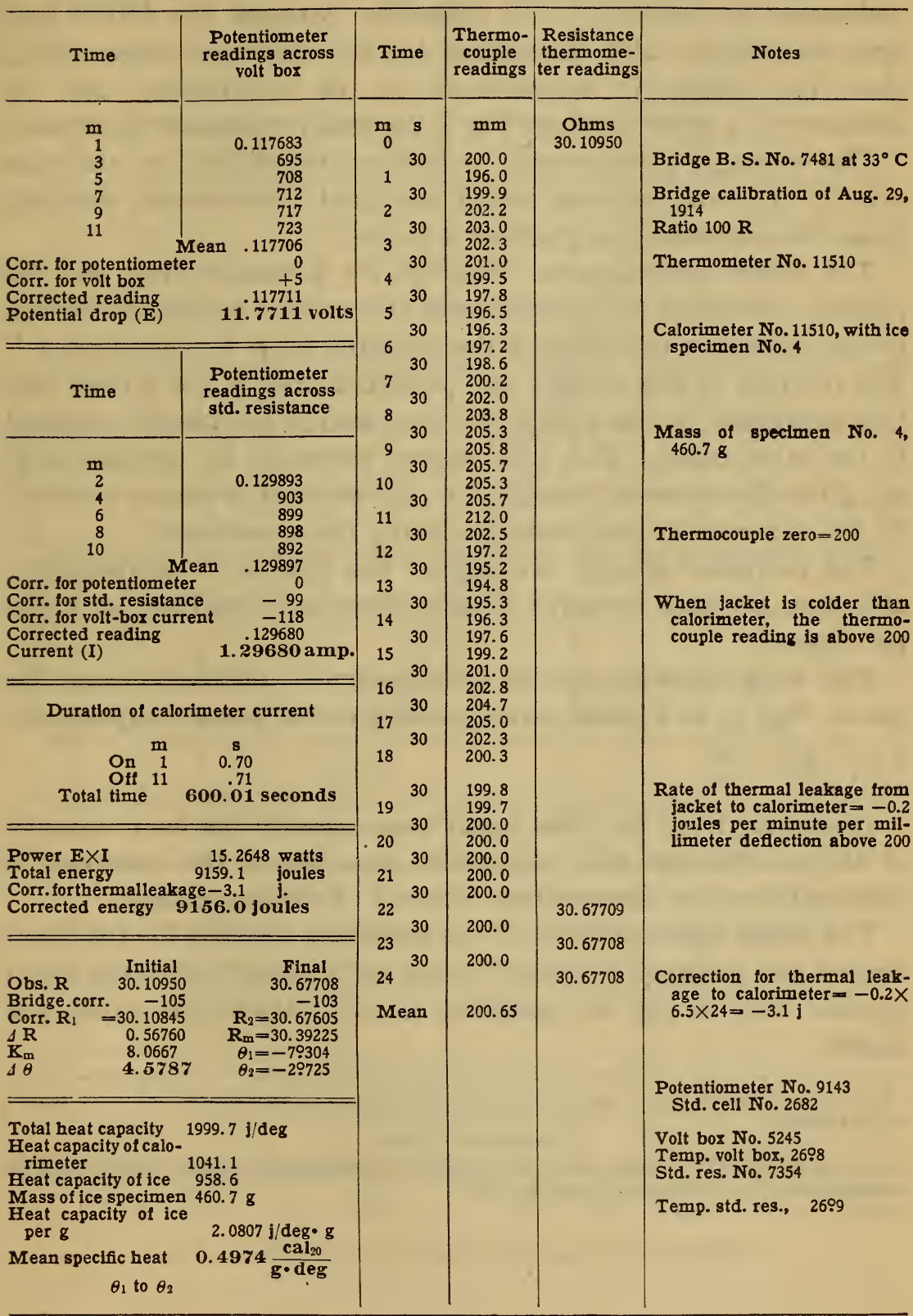

FIG. 3.-Sample record of experiment 
The initial and final readings of thermometer resistance corrected for bridge errors give the initial and final thermometer resistances $R_{1}$ and $R_{2}$. The difference between the initial and final resistances, $\Delta R$, multiplied by the difference factor, $K_{m}$, gives the change in temperature of the calorimeter, $\Delta \theta$. In obtaining $K_{m}$ from the chart Fig. 4 the mean resistance $R_{m}$ is used.

The average thermocouple deflection multiplied by the rate and by the time between initial and final thermometer readings gives the correction for thermal leakage.

The mean potentiometer readings for potential drop and for current, corrected for instrumental errors, and multiplied by the proper reduction factors, give the potential drop, $E$, and current $I$. The product of the current and potential drop is the power, and this multiplied by the time is the total energy electrically supplied to the calorimeter. This total energy corrected for thermal leakage gives the corrected energy, i. e., the amount of energy received by the calorimeter and contents during the experiment.

The corrected energy divided by the change in temperature, $\Delta \theta$, gives the heat capacity of calorimeter and specimen in joules per degree.

The heat capacity of the calorimeter is obtained from the curve, Fig. 5, at a point corresponding to the mean temperature, $\frac{1}{2}\left(\theta_{1}+\theta_{2}\right)$.

Deducting from the total mean heat capacity the heat capacity of the calorimeter, the mean heat capacity of the specimen is obtained over the temperature interval of the experiment.

The mean heat capacity of the specimen divided by the mass and by the number of joules ${ }^{15}$ in one $20^{\circ}$ calorie, ${ }^{16}$ gives the mean specific heat of the ice specimen in $20^{\circ}$ calories per gram per degree.

15 The relation between the $20^{\circ}$ calorie and the joule (international watt second) is taken as represented by the equation

$I$ calorie $20=4.183$ joules

16 The $20^{\circ}$ calorie used in this paper is taken as the quantity of heat per gram (mass) per degree centigrade required to raise the temperature of water at $20^{\circ} \mathrm{C}$. 


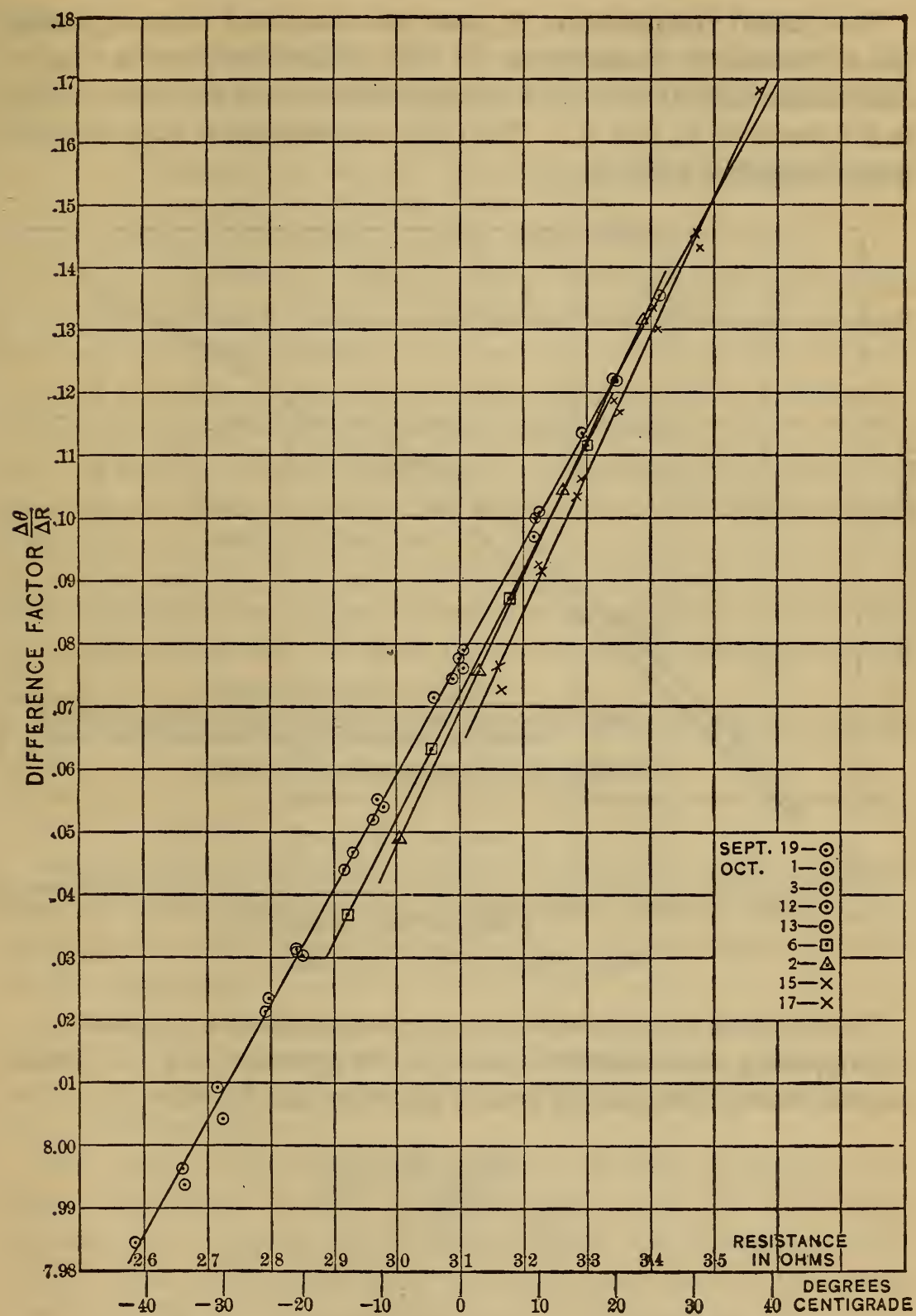

FIG. 4.-Calibration of resistance thermometer in calorimeter 
The initial temperature, $\theta_{1}$, may be computed from $R_{1}$, using the thermometer resistance at $0^{\circ}\left(R_{0}\right)$, determined at the time of calibration, and the value $\mathrm{K}$ corresponding to a resistance which is the mean of $R_{0}$ and $R_{1}$. The final temperature $\theta_{2}$ may be computed similarly from $R_{2}$.

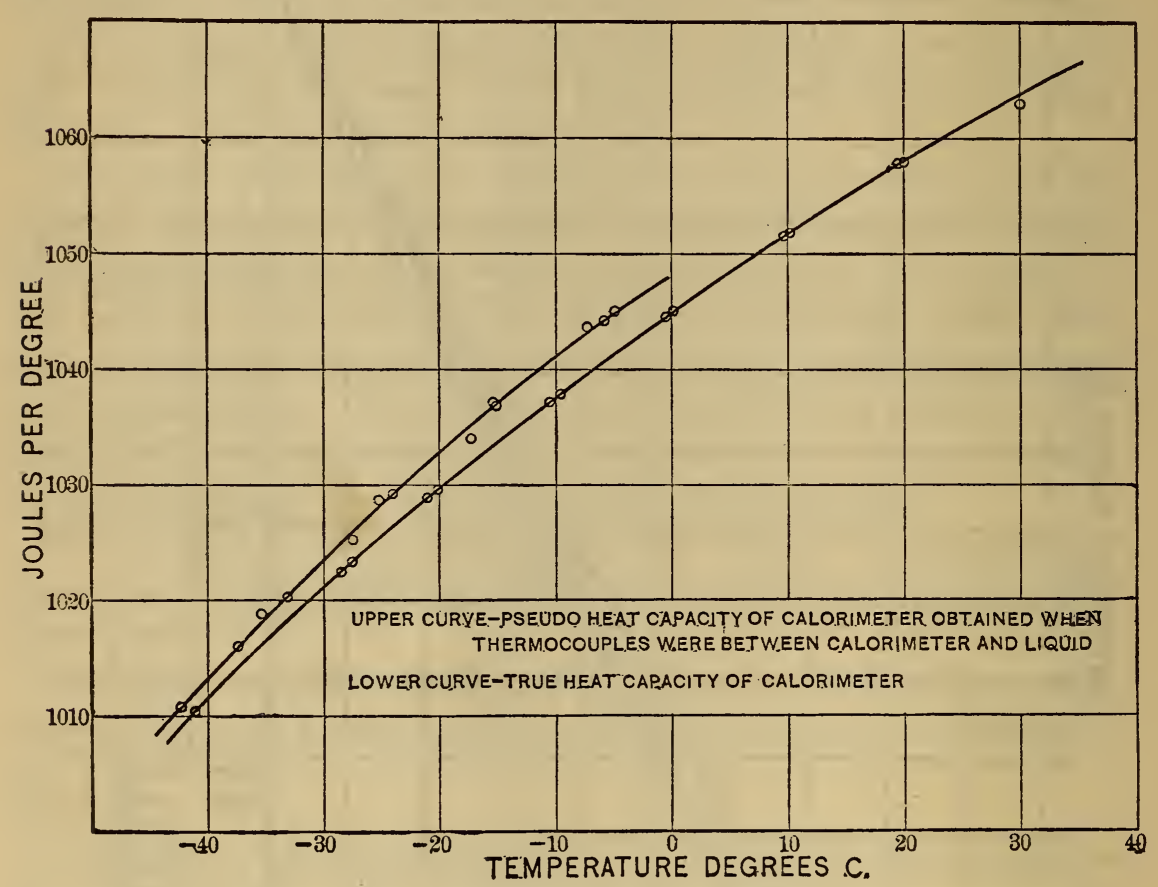

FIG. 5.-Heat capacity of calorimeter

The method of calculation may be summarized as follows:

Supposing the observed data to be corrected for all instrumental errors, the specific heat is given by the formula

$$
S=\frac{\frac{I E T+B t d}{\Delta R K_{m}}}{M J}-C
$$


where

$S=$ mean specific heat of specimen in $20^{\circ}$ calories per gram per degree over the interval of temperature employed.

$C=$ mean heat capacity of calorimeter in joules per degree.

$I=$ current in amperes (mean value).

$E=$ potential drop in volts (mean value).

$T=$ duration of energy supply to calorimeter in seconds.

$d=$ average thermocouple deflection in millimeters during experiment.

$t=$ time in minutes between initial and final readings of calorimeter resistance thermometer.

$B=$ rate of thermal leakage to calorimeter from surroundings in joules per minute per millimeter thermocouple deflection.

$R_{1}=$ initial resistance of thermometer in ohms.

$R_{2}=$ final resistance of thermometer in ohms.

$\Delta R=$ difference between initial and final resistance of the thermometer in ohms.

$K_{m}=$ the difference factor for the resistance thermometer, i. e., $\frac{\Delta \theta}{\Delta R}$ in degrees per ohm.

$M=$ mass of specimen in grams.

The current and potential drop were always so nearly constant that the approximation in taking the product of their mean values multiplied by the time as the total energy is well within the limit of allowable error.

A complete description of the method and results of the calibration of the calorimeter resistance thermometer and of the determinations of the heat capacity of the calorimeter are given in a preceding paper. ${ }^{17}$

The values of the difference factor $K$ as there determined are given graphically in Fig. 4. This chart was used in making calculations of specific heat determinations, the difference factor for any observed interval being taken from the curve at the point corresponding to the mean between the initial and final thermometer resistances. Since the performance of the thermometer

${ }^{17}$ Dickinson and Osborne, this Bulletin, 12, p. 23, 1915, Scientific Paper No. 24\%. $6844^{\circ}-15-5$ 
was found to depend upon the previous thermal treatment, in the use of the chart the appropriate calibration line was chosen to correspond with the initial temperature of the experiments on the particular day.

The values of the heat capacity of the calorimeter are given graphically in Fig. 5. The two curves there shown represent the values obtained with the two arrangements of the thermocouples which were used in the determinations. When the earlier arrangement was used, consisting of a single set of thermocouples, the junctions of which were so placed as to indicate the difference in temperature between the surface of the calorimeter and a point in the liquid near the jacket, the upper curve was obtained. The lower curve was obtained with the later arrangement, making use of an additional set of couples the junctions of which were so placed that when joined in series the two sets of couples indicated the difference in temperature between the calorimeter and the jacket surfaces.

These later results showed that in the original arrangement the true temperature difference between calorimeter and jacket had not been indicated owing to the effect of lag in liquid and jacket. The significance of this fault in the apparatus did not appear until after the experimental work on samples $\mathrm{I}, 2$, and 3 had been completed, but errors from this cause in the final results for these samples could be avoided in the manner explained below.

The value of the observed total heat capacity of the empty calorimeter and of the calorimeter containing a specimen would be affected to the same extent by the improper placing of the thermocouple, provided that in the two experiments the manipulation of the jacket was similar. If, therefore, in computing the result of a specific heat determination a value of heat capacity of the calorimeter be used, determined under experimental conditions similar to those in the specific heat determination, no error is introduced into the resulting value of specific heat. It was necessary therefore to employ the false values of heat capacity shown by the upper curve in Fig. 5 in computing the earlier results.

It was ascertained that the variations in manipulation which did occur, such as the use of different amounts of refrigeration and compensating heating, etc., were not sufficient to cause any large systematic error. 


\section{SPECIFIC HEAT OF ICE}

Experimental Results.-The results of experiments to determine the specific heat of ice are given in Tables 2, 4, 6, and 8 , in which the observed mean specific heats of the several samples are expressed with reference to the initial and final temperatures $\theta_{1}, \theta_{2}$ of the respective experiments $\left(S_{\mathrm{m}}=\frac{H_{2}-H_{1}}{\theta_{2}-\theta_{1}}\right.$, where $H_{2}-H_{1}$ represents the total heat per gram over the interval $\theta_{2}-\theta_{1}$ ).

\section{TABLE 2}

\section{Determinations of Specific Heat of Ice}

Sample No. 1, Experimental Results

[Mass, 468.7 grams]

\begin{tabular}{|c|c|c|c|c|c|c|c|c|c|c|c|}
\hline Date & Exp & $\begin{array}{c}\text { Total } \\
\text { energy }\end{array}$ & $\begin{array}{c}\text { Cor- } \\
\text { rection } \\
\text { for } \\
\text { ther- } \\
\text { mal } \\
\text { leak- } \\
\text { age }\end{array}$ & $\begin{array}{l}\text { Cor- } \\
\text { rected } \\
\text { total } \\
\text { energy }\end{array}$ & $\begin{array}{c}\text { Inltial } \\
\text { tem- } \\
\text { pera- } \\
\text { ture } \\
\theta_{1}\end{array}$ & $\begin{array}{c}\text { Final } \\
\text { tem- } \\
\text { pera- } \\
\text { ture } \\
\theta_{2}\end{array}$ & $\begin{array}{c}\text { Tem- } \\
\text { perature } \\
\text { differ- } \\
\text { ence } \\
\theta_{2} \text { to } \theta_{1}\end{array}$ & $\begin{array}{c}\text { Total } \\
\text { mean } \\
\text { heat } \\
\text { capacity } \\
\theta_{1} \text { to } \theta_{2}\end{array}$ & $\begin{array}{c}\text { Mean } \\
\text { heat } \\
\text { capacity } \\
\text { of calo- } \\
\text { rimeter } \\
\theta_{1} \text { to } \theta_{2}\end{array}$ & $\begin{array}{c}\text { Mean } \\
\text { heat } \\
\text { capacity } \\
\text { of ice } \\
\theta_{1} \text { to } \theta_{2} \\
\mathrm{j} / \mathrm{deg}\end{array}$ & $\begin{array}{c}\text { Mean } \\
\text { specific } \\
\text { heat } \\
\theta_{1} \text { to } \theta_{2} \\
S_{\mathrm{m}}\end{array}$ \\
\hline 1914 & & joules & joules & joules & $\operatorname{deg} C$ & $\operatorname{deg} C$ & $\operatorname{deo} C$ & j/deg & jldeg & j/deg & $\frac{\text { cal }_{20}}{0^{\circ} d e g}$ \\
\hline \multirow[t]{9}{*}{ June 2} & 1 & 19245.7 & +22.3 & 19268 & -41.840 & -31.559 & 10.281 & 1874.1 & 1016.5 & 857.6 & 0.4374 \\
\hline & 2 & 19212.9 & -3.5 & 19209 & 31.559 & 21.553 & 10.006 & 1919.7 & 1026.7 & 893.0 & .4555 \\
\hline & 3 & 19162.3 & +0.8 & 19163 & 21.548 & 11.799 & 9.7495 & 1965.5 & 1035.4 & 930.1 & .4744 \\
\hline & 4 & 9574.3 & -1.0 & 9573 & 11.799 & 7.014 & 4. 7848 & 2000.7 & 1041.2 & 960.5 & .4899. \\
\hline & 5 & 5740.7 & 0.0 & 5740.7 & 7.016 & 4.182 & 2. 8339 & 2025.7 & 1044.2 & 981.5 & .5006 \\
\hline & 6 & 3816.7 & 0.0 & 3816.7 & 4. 183 & 2.327 & 1.8564 & 2056.0 & 1045.7 & 1010.3 & .5153 \\
\hline & 7 & 1909.3 & +3.2 & 1912.5 & 2.327 & 1.419 & .9079 & 2106.5 & 1046.5 & 1060.0 & .5407 \\
\hline & 8 & 1909.0 & +6.1 & 1915.1 & 1.419 & .583 & .8362 & 2290.2 & 1047.0 & 1243.2 & .6341 \\
\hline & 9 & 953.9 & +12.2 & 966.1 & .584 & .284 & .3001 & 3219.3 & 1047.4 & 2171.9 & 1.1078 \\
\hline \multirow[t]{9}{*}{ June 3} & 1 & 19106.4 & +34.3 & 19141 & -41.853 & -31.648 & 10.205 & 1875.6 & 1016.5 & 859.1 & .4382 \\
\hline & 2 & 19055.0 & +0.6 & 19056 & 31.648 & 21.729 & 9.9188 & 1921.2 & 1026.7 & 894.5 & .4563 \\
\hline & 3 & 19084.8 & -3.9 & 19081 & 21.726 & 12.016 & 9. 7100 & 1965.1 . & 1035.2 & 929.9 & .4743 \\
\hline & 4 & 9483.5 & -3.4 & 9480 & 12.017 & 7.279 & 4.7378 & 2000.9 & 1041.1 & 959.8 & .4896 \\
\hline & 5 & 5763.7 & 0.0 & 5763.7 & 7.279 & 4.430 & 2.8488 & 2023.2 & 1043.8 & 979.4 & .4996 \\
\hline & 6 & 3801.6 & +3.1 & 3804.7 & 4.430 & 2.570 & 1.8608 & 2044.7 & 1045.6 & 999.1 & .5096 \\
\hline & 7 & 1988.4 & +2.8 & 1991.2 & 2.570 & 1.614 & .9558 & 2083.3 & 1046.5 & 1036.8 & .5289 \\
\hline & 8 & 1988.1 & -1.6 & 1986.5 & 1.615 & .714 & .9012 & 2204.3 & 1047.0 & 1157.3 & .5903 \\
\hline & 9 & 993.2 & +1.8 & 995.0 & .714 & .356 & .3581 & 2778.6 & 1047.4 & 1731.2 & .8830 \\
\hline
\end{tabular}




\section{TABLE 3}

\section{Specific Heat of Ice}

Sample No. 1, Reduction of Results

\begin{tabular}{|c|c|c|c|c|c|c|c|c|c|}
\hline $\begin{array}{c}\text { Initial } \\
\text { tem- } \\
\text { pera- } \\
\text { ture } \\
\theta_{1}\end{array}$ & $\begin{array}{c}\text { Final } \\
\text { tempera- } \\
\text { ture } \\
\theta_{2}\end{array}$ & $\sqrt{\theta_{1} \theta_{2}}=\theta$ & $\frac{\theta_{1}+\theta_{2}}{2}=\theta^{\prime}$ & $\theta-\theta^{\prime}$ & $\mathbf{A}\left(\theta-\theta^{\prime}\right)$ & $\begin{array}{c}\text { Mean } \\
\text { specific } \\
\text { heat } \\
\theta_{1} \text { to } \theta_{2}= \\
\mathrm{S}_{\mathrm{m}}\end{array}$ & $\begin{array}{c}\text { Specific } \\
\text { heat } \\
\text { corrected } \\
\text { to } \theta \\
\mathbf{s}^{\text {obs }}\end{array}$ & ${ }^{s} \theta_{\text {calc. }}$ & $\begin{array}{l}\mathbf{s}_{\theta_{\text {obs }}-} \\
\mathbf{s}_{\theta_{\text {calc. }}}\end{array}$ \\
\hline $\operatorname{deg} C$ & $\operatorname{deg} C$ & $\operatorname{deg} C$ & $\operatorname{deg} C$ & $\operatorname{deg} C$ & & $\frac{c a l_{20}}{\sigma \cdot d e g}$ & 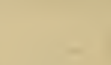 & & \\
\hline-41.840 & -31.559 & -36.338 & -36.700 & 0.362 & 0.0007 & 0.4374 & 0.4381 & 0.4381 & 0.0000 \\
\hline 41.853 & 31.648 & 36.395 & 36.750 & .355 & .0007 & .4382 & .4389 & .4380 & +.0009 \\
\hline 31.559 & 21.553 & 26.080 & 26.556 & .476 & .0009 & .4555 & .4564 & .4572 & -.0008 \\
\hline 31.648 & 21.729 & 26.224 & 26.688 & .464 & .0009 & .4563 & .4572 & .4569 & +.0003 \\
\hline 21.548 & 11.799 & 15.945 & 16.674 & .729 & .0014 & .4744 & .4758 & .4764 & -.0006 \\
\hline 21.726 & 12.016 & 16.157 & 16.871 & .714 & .0013 & .4743 & .4756 & .4760 & -.0004 \\
\hline 11.799 & 7.014 & 9.097 & 9.406 & .309 & .0006 & . 4899 & .4905 & .4900 & +.0005 \\
\hline 12.017 & 7.279 & 9.353 & 9.648 & .295 & .0006 & .4896 & .4902 & .4894 & +.0008 \\
\hline 7.016 & 4.182 & 5.417 & 5.599 & .182 & .0003 & .5006 & .5009 & .4990 & +.0019 \\
\hline 7.279 & 4.430 & 5.679 & 5.854 & .176 & .0003 & .4996 & .4999 & .4982 & +.0017 \\
\hline 4.183 & 2.327 & 3.120 & 3.255 & .135 & .0003 & .5153 & .5156 & .5101 & +.0055 \\
\hline 4.430 & 2.570 & 3.374 & 3.500 & .126 & .0002 & .5096 & .5098 & .5081 & +.0017 \\
\hline 2.327 & 1.419 & 1.817 & 1.873 & .056 & .0001 & .5407 & .5408 & .5325 & +.0083 \\
\hline 2.570 & 1.614 & 2.037 & 2.092 & .055 & .0001 & .5289 & .5290 & .5261 & +.0029 \\
\hline 1.419 & .583 & $.909_{5}$ & 1.001 & .092 & .0002 & .6341 & .6343 & .6244 & +.0099 \\
\hline 1.615 & .714 & 1.074 & 1.164 & .090 & .0002 & .5903 & .5905 & .5901 & +.0004 \\
\hline .584 & .284 & $.407_{3}$ & .434 & .027 & .0001 & 1.1078 & 1.1079 & 1.1059 & +.0020 \\
\hline .714 & .356 & $.504 \Omega$ & .535 & .031 & .0001 & .8830 & .8831 & .8966 & -.0135 \\
\hline
\end{tabular}


TABLE 4

\section{Determinations of Specific Heat of Ice}

Sample No. 2, Experimental Resuits

[Mass, 399.8 grams]

\begin{tabular}{|c|c|c|c|c|c|c|c|c|c|c|c|}
\hline Date & $\operatorname{Exp}$ & $\begin{array}{c}\text { Total } \\
\text { energy }\end{array}$ & $\begin{array}{c}\text { Cor- } \\
\text { rection } \\
\text { for } \\
\text { ther- } \\
\text { mal } \\
\text { leak- } \\
\text { age }\end{array}$ & $\begin{array}{l}\text { Cor- } \\
\text { rected } \\
\text { total } \\
\text { energy }\end{array}$ & $\begin{array}{c}\text { Initial } \\
\text { tem- } \\
\text { pera- } \\
\text { ture } \\
\theta_{1}\end{array}$ & $\begin{array}{c}\text { Final } \\
\text { tem- } \\
\text { pera- } \\
\text { ture } \\
\theta_{2}\end{array}$ & $\begin{array}{c}\text { Tem- } \\
\text { perature } \\
\text { differ- } \\
\text { ence } \\
\theta_{2}-\theta_{1}\end{array}$ & $\begin{array}{c}\text { Total } \\
\text { mean } \\
\text { heat } \\
\text { capacity } \\
\theta_{1} \text { to } \theta_{2}\end{array}$ & $\begin{array}{c}\text { Mean } \\
\text { heat } \\
\text { capacity } \\
\text { of calo- } \\
\text { rimeter } \\
\theta_{1} \text { to } \theta_{2}\end{array}$ & $\begin{array}{c}\text { Mean } \\
\text { heat } \\
\text { capacity } \\
\text { of ice } \\
\theta_{1} \text { to } \theta_{2}\end{array}$ & $\begin{array}{l}\text { Mean } \\
\text { specific } \\
\text { heat } \\
\theta_{1} \text { to } \theta_{2} \\
\mathrm{~S}_{\mathrm{m}}\end{array}$ \\
\hline 1914 & & joules & joules & joules & $\operatorname{deg} C$ & $\operatorname{deg} C$ & $\operatorname{deg} C$ & $j / d e g$ & j/deg & $j / d e g$ & $\frac{\operatorname{cal}_{20}}{g \cdot \operatorname{deg}}$ \\
\hline \multirow[t]{6}{*}{ June 12} & 1 & 18068.7 & +0.5 & 18069 & -45.509 & -35.094 & 10.416 & 1734.8 & 1012.8 & 722.0 & 0.4317 \\
\hline & 2 & 18060.5 & +4.8 & 18065 & 35.094 & 24.915 & 10.178 & 1774.9 & 1023.5 & 751.4 & .4493 \\
\hline & 3 & 18042.8 & -4.2 & 18039 & 24.915 & 14.974 & 9.9412 & 1814.6 & 1032.7 & 781.9 & .4676 \\
\hline & 4 & 18035.3 & -11.8 & 18023 & 14.974 & 5.262 & 9.7118 & 1855.8 & 1040.7 & 815.1 & .4874 \\
\hline & 6 & 3604.1 & -1.1 & 3603.0 & 3. 344 & 1.459 & 1.8853 & 1911.1 & 1046.2 & 864.9 & .5172 \\
\hline & 7 & 1914.6 & -0.3 & 1914.3 & 1.459 & .530 & .9289 & 2060.8 & 1047.1 & 1013.7 & .6062 \\
\hline \multirow[t]{6}{*}{ June 13} & 1 & 18352.7 & -9.1 & 18344 & -26.561 & -16.409 & 10.152 & 1807.0 & 1031.3 & 775.7 & .4639 \\
\hline & 2 & 18311.8 & 0.0 & 18312 & 16.371 & 6.470 & 9.9013 & 1849.5 & 1039.6 & 809.9 & .4843 \\
\hline & 3 & 5487.6 & +2.6 & 5490.2 & 6.470 & 3.551 & 2.9189 & 1880.9 & 1044.7 & 836.2 & .5000 \\
\hline & 4 & 5484.9 & -2.2 & 5482.7 & 3. 551 & .722 & 2.8286 & 1938.3 & 1046.5 & 891.8 & .5333 \\
\hline & 5 & 914.7 & -4.2 & 910.5 & .722 & .352 & .3702 & 2459.5 & 1047.3 & 1412.2 & .8445 \\
\hline & 6 & 456.3 & +1.0 & 457.3 & .352 & .238 & .1137 & 4022.0 & 1047.5 & 2974.5 & 1.779 \\
\hline
\end{tabular}

\section{TABLE 5}

\section{Specific Heat of Ice}

Sample No. 2, Reduction of Results

\begin{tabular}{|c|c|c|c|c|c|c|c|c|c|}
\hline $\begin{array}{c}\text { Initial } \\
\text { tem- } \\
\text { pera- } \\
\text { ture } \\
\theta_{1}\end{array}$ & $\begin{array}{c}\text { Final } \\
\text { tempera- } \\
\text { ture } \\
\theta_{2}\end{array}$ & $\sqrt{\theta_{1} \theta_{2}}=\theta$ & $\frac{\theta_{1}+\theta_{2}}{2}=\theta^{\prime}$ & $\theta-\theta^{\prime}$ & $\mathbf{A}\left(\theta-\theta^{\prime}\right)$ & $\begin{array}{c}\text { Mean } \\
\text { specific } \\
\text { heat } \\
\theta_{1} \text { to } \theta_{2}= \\
\mathrm{s}_{\mathrm{m}}\end{array}$ & $\begin{array}{c}\text { Specific } \\
\text { heat } \\
\text { corrected } \\
\text { to } \theta \\
\mathrm{s}_{\theta \mathrm{obs}}\end{array}$ & ${ }^{s} \theta_{\text {calc. }}$ & ${ }^{\mathrm{s}_{\theta_{\text {obs }}-}}$ \\
\hline $\operatorname{deg} C$ & $\operatorname{deg} C$ & $\operatorname{deg} C$ & $\operatorname{deg} C$ & $\operatorname{deg} C$ & & $\frac{\mathrm{cal}_{20}}{\mathrm{o} \cdot \mathrm{deg}}$ & & & \\
\hline-45.509 & -35.094 & -39.964 & -40.302 & 0.338 & 0.0006 & 0.4317 & 0.4323 & 0.4313 & +0.0010 \\
\hline 35.094 & 24.915 & 29.570 & 30.004 & .434 & .0008 & .4493 & .4501 & .4507 & -.0006 \\
\hline 26.561 & 16.409 & 20.877 & 21.485 & .608 & .0011 & .4639 & .4650 & .4670 & -.0020 \\
\hline 24.915 & 14.974 & 19.315 & 19.944 & .629 & .0012 & .4676 & .4688 & .4700 & -.0012 \\
\hline 16.371 & 6.470 & 10.292 & 11.420 & 1.128 & .0021 & .4843 & .4864 & .4874 & -.0010 \\
\hline 14.974 & 5.262 & 8.877 & 10.118 & 1.241 & .0023 & .4874 & .4897 & .4904 & -.0007 \\
\hline 6.470 & 3.551 & 4.793 & 5.010 & .217 & .0004 & .5000 & .5004 & .5007 & -.0003 \\
\hline 3.551 & .722 & 1.601 & 2.136 & .535 & .0010 & .5333 & .5343 & .5399 & -.0056 \\
\hline 3. 344 & 1.459 & 2.209 & 2.402 & .193 & .0004 & .5172 & .5176 & .5212 & -.0136 \\
\hline 1.459 & .530 & .879 & .994 & .115 & .0002 & .6062 & .6064 & .6282 & -.0218 \\
\hline .722 & .352 & $.504_{1}$ & .537 & .033 & .0001 & .8445 & .8446 & .8812 & -.0366 \\
\hline .352 & .238 & .289 & .295 & .006 & .0000 & 1.779 & 1.779 & 1.6522 & +.1268 \\
\hline
\end{tabular}


TABLE 6

Determinations of Specific Heat on Ice

Sample No. 3, Experimental Results

[Mass, 4r5.8 grams]

\begin{tabular}{|c|c|c|c|c|c|c|c|c|c|c|c|}
\hline Date & Exp & $\begin{array}{c}\text { Total } \\
\text { energy }\end{array}$ & $\begin{array}{c}\text { Cor- } \\
\text { rection } \\
\text { for } \\
\text { ther- } \\
\text { mal } \\
\text { leak- } \\
\text { age }\end{array}$ & $\begin{array}{c}\text { Cor- } \\
\text { rected } \\
\text { total } \\
\text { energy }\end{array}$ & $\begin{array}{c}\text { Initial } \\
\text { tem- } \\
\text { pera- } \\
\text { ture } \\
\theta_{1}\end{array}$ & $\begin{array}{c}\text { Final } \\
\text { tem- } \\
\text { pera- } \\
\text { ture } \\
\theta_{2}\end{array}$ & $\begin{array}{c}\text { Tem- } \\
\text { perature } \\
\text { differ- } \\
\text { ence } \\
\theta_{2} \text { to } \theta_{1}\end{array}$ & $\begin{array}{c}\text { Total } \\
\text { mean } \\
\text { heat } \\
\text { capacity } \\
\theta_{1} \text { to } \theta_{2}\end{array}$ & $\begin{array}{c}\text { Mean } \\
\text { heat } \\
\text { capacity } \\
\text { of calo- } \\
\text { rimeter } \\
\theta_{1} \text { to } \theta_{2}\end{array}$ & $\begin{array}{c}\text { Mean } \\
\text { heat } \\
\text { capacity } \\
\text { of ice } \\
\theta_{1} \text { to } \theta_{2}\end{array}$ & $\begin{array}{c}\text { Mean } \\
\text { specific } \\
\text { heat } \\
\theta_{1} \text { to } \theta_{2} \\
\mathbf{S}_{m}\end{array}$ \\
\hline 1914 & & joules & joules & joules & $\operatorname{deg} C$ & $\operatorname{deg} C$ & $\operatorname{deg} C$ & $j /$ deg & $j / d e g$ & $j / d e g$ & $\frac{\mathrm{cal}_{20}}{g \cdot \mathrm{deg}}$ \\
\hline \multirow[t]{7}{*}{ June 17} & 1 & 20120. & -6.0 & 20114. & -43.284 & -31.964 & 11.320 & 1776.8 & 1015.7 & 761.1 & 0.4376 \\
\hline & 2 & 18685.8 & -9.2 & 18677. & 31.956 & 21.701 & 10.2546 & 1821.3 & 1026.5 & 794.8 & .4570 \\
\hline & 3 & 18662.4 & +0.6 & 18663. & 21.701 & 11.689 & 10.0121 & 1864.0 & 1035.6 & 828.4 & .4763 \\
\hline & 4 & 9325.1 & +0.8 & 9326. & 11.689 & 6.769 & 4.9202 & 1895.5 & 1041.6 & 853.9 & .4910 \\
\hline & 5 & 5593.2 & -0.9 & 5592.3 & 6.769 & 3.848 & 2.9213 & 1914.3 & 1044.5 & 869.8 & .5001 \\
\hline & 6 & 3726.8 & -1.1 & 3725.7 & 3.848 & 1.924 & 1.9240 & 1936.4 & 1046.0 & 890.4 & .5120 \\
\hline & 7 & 1931.6 & -2.4 & 1929.2 & 1.924 & .954 & .9690 & 1990.9 & 1046.7 & 944.2 & .5429 \\
\hline \multirow[t]{7}{*}{ June 18} & 1 & 18620.4 & -1.2 & 18619. & -16.720 & -6.800 & 9.9206 & 1876.8 & 1039.9 & 836.9 & .4812 \\
\hline & 2 & 5664.6 & 0.0 & 5664.6 & 6.809 & 3.847 & 2.9619 & 1912.5 & 1044.4 & 868.1 & . 4991 \\
\hline & 3 & 1912.4 & -1.9 & 1910.5 & 3.847 & 2.857 & .9902 & 1929.4 & 1045.6 & 883.8 & .5082 \\
\hline & 4 & 1913.1 & +.9 & 1914.0 & 2.857 & 1.873 & .9844 & 1944.3 & 1046.1 & 898.2 & .5164 \\
\hline & 5 & 1899.5 & -1.4 & 1898.1 & 1.877 & .925 & .9521 & 1993.6 & 1046.7 & 946.9 & .5444 \\
\hline & 6 & 952.2 & -1.5 & 951.7 & .925 & .494 & .4309 & 2208.6 & 1047.1 & 1161.5 & .6678 \\
\hline & 7 & 951.3 & 0.0 & 951.3 & .495 & .211 & .2837 & 3353.2 & 1047.2 & 2306.0 & 1. 3259 \\
\hline
\end{tabular}

TABLE 7

Specific Heat of Ice

Sample No. 3, Reduction of Results

\begin{tabular}{|c|c|c|c|c|c|c|c|c|c|}
\hline $\begin{array}{c}\text { Initial } \\
\text { tem- } \\
\text { pera- } \\
\text { ture } \\
\theta_{1}\end{array}$ & $\begin{array}{c}\text { Final } \\
\text { tempera- } \\
\text { ture } \\
\theta_{2}\end{array}$ & $\sqrt{\theta_{1} \theta_{2}}=\theta$ & $\frac{\theta_{1}+\theta_{2}}{2}=\theta^{\prime}$ & $\theta-\theta^{\prime}$ & $\mathbf{A}\left(\theta-\theta^{\prime}\right)$ & $\begin{array}{c}\text { Mean } \\
\text { specific } \\
\text { heat } \\
\theta_{1} \text { to } \theta_{2}= \\
\mathrm{S}_{\text {m }}\end{array}$ & $\begin{array}{c}\begin{array}{c}\text { Specific } \\
\text { heat } \\
\text { corrected } \\
\text { to } \theta \\
s^{\theta o b s}\end{array} \\
\text { o }\end{array}$ & $s_{\theta \text { calc. }}$ & $\begin{array}{l}\mathrm{s}_{\theta_{\mathrm{obs}}-} \\
\mathrm{s}_{\theta_{\text {calc. }}}\end{array}$ \\
\hline $\operatorname{deg} C$ & $\operatorname{deg} C$ & $\operatorname{deg} C$ & $\operatorname{deg} C$ & $\operatorname{deg} C$ & & $\frac{c a l_{20}}{g \cdot d e g}$ & & & \\
\hline-43.284 & -31.964 & 37.196 & 37.624 & 0.428 & 0.0008 & 0.4376 & 0.4384 & 0.4366 & +0.0018 \\
\hline 31.956 & 21.701 & 26.334 & 26.828 & .494 & .0009 & .4570 & .4579 & .4566 & +.0013 \\
\hline 21.701 & 11.689 & 15.927 & 16.695 & .768 & .0014 & .4763 & .4777 & .4760 & +.0017 \\
\hline 16.720 & 6.800 & 10.663 & 11.760 & 1.097 & .0020 & .4812 & .4832 & $.485 \Omega$ & -.0027 \\
\hline 11.689 & 6.769 & 8.895 & 9.229 & .334 & .0006 & .4910 & .4916 & .4892 & +.0024 \\
\hline 6.769 & 3.848 & 5.104 & 5.308 & .204 & .0004 & .5001 & .5005 & .4965 & +.0040 \\
\hline 6.809 & 3.847 & 5.118 & 5.328 & .210 & .0004 & .4991 & .4995 & .4965 & +.0030 \\
\hline 3.848 & 1.924 & 2.721 & 2.886 & .165 & .0003 & .5120 & .5123 & .5108 & +.0015 \\
\hline 3.847 & 2.857 & 3. 315 & 3.352 & .037 & .0001 & .5082 & .5083 & .5064 & +.0019 \\
\hline 2.857 & 1.873 & 2.313 & 2.365 & .052 & .0001 & .5164 & .5165 & .5155 & +.0010 \\
\hline 1.924 & .954 & 1.355 & 1.439 & .084 & .0002 & .5429 & .5431 & .5444 & -.0013 \\
\hline 1.877 & .925 & 1.318 & 1.401 & .083 & .0002 & .5444 & .5446 & .5468 & -.0022 \\
\hline .925 & .494 & .676 & .710 & .034 & .0001 & .6678 & .6679 & .6701 & -.0022 \\
\hline .495 & .211 & .3232 & .353 & .030 & .0001 & 1.3259 & 1.3260 & 1.2311 & +.0949 \\
\hline
\end{tabular}




\section{TABLE 8}

\section{Determinations of Specific Heat of Ice}

Sample No. 4, Experimental Results

[Mass, 460.7 grams]

\begin{tabular}{|c|c|c|c|c|c|c|c|c|c|c|c|}
\hline Date & Exp & $\begin{array}{c}\text { Total } \\
\text { energy }\end{array}$ & $\begin{array}{c}\text { Cor- } \\
\text { rection } \\
\text { for } \\
\text { ther- } \\
\text { mal } \\
\text { leak- } \\
\text { ago }\end{array}$ & $\begin{array}{c}\text { Cor- } \\
\text { rected } \\
\text { total } \\
\text { energy }\end{array}$ & $\begin{array}{c}\text { Initial } \\
\text { tem- } \\
\text { pera- } \\
\text { ture } \\
\theta_{1}\end{array}$ & $\begin{array}{c}\text { Final } \\
\text { tem- } \\
\text { pera- } \\
\text { ture } \\
\theta_{2}\end{array}$ & $\begin{array}{c}\text { Tem- } \\
\text { perature } \\
\text { differ- } \\
\text { ence } \\
\theta_{2} \text { to } \theta_{1}\end{array}$ & $\begin{array}{c}\text { Total } \\
\text { mean } \\
\text { heat } \\
\text { capacity } \\
\theta_{1} \text { to } \theta_{2}\end{array}$ & $\begin{array}{c}\text { Mean } \\
\text { heat } \\
\text { capacity } \\
\text { of calo- } \\
\text { rimeter } \\
\theta_{1} \text { to } \theta_{2}\end{array}$ & $\begin{array}{c}\text { Mean } \\
\text { heat } \\
\text { capacity } \\
\text { of ice } \\
\theta_{1} \text { to } \theta_{2}\end{array}$ & $\begin{array}{c}\text { Mean } \\
\text { specific } \\
\text { heat } \\
\theta_{1} \text { to } \theta_{2}\end{array}$ \\
\hline 1914 & & joules & joules & joules & $\begin{array}{l}\operatorname{deg} C \\
(-)\end{array}$ & $\begin{array}{l}\operatorname{deg} C \\
(-)\end{array}$ & $\operatorname{deg} C$ & $j /$ deg & $j / d e g$ & $j / d e g$ & $\frac{\mathrm{cal}_{20}}{g \cdot d e g}$ \\
\hline \multirow[t]{7}{*}{ Aug. 5} & 1 & 15167.4 & +6.2 & 15174 & 36.0626 & 27.9733 & 8.0893 & 1875.8 & 1018.5 & 857.3 & 0.4449 \\
\hline & 2 & 15156.1 & +2.6 & 15159 & 27.9733 & 20.0447 & 7.9286 & 1911.9 & 1026.8 & 885.1 & .4593 \\
\hline & 3 & 17942.7 & -2.2 & 17941 & 19.8574 & 10.6655 & 9.1919 & 1951.8 & 1033.3 & 918.5 & .4766 \\
\hline & 4 & 8959.0 & -1.2 & 8957.8 & 10.6655 & 6.1438 & 4.5217 & 1981.1 & 1038.7 & 942.4 & .4890 \\
\hline & 5 & 4468.6 & +2.9 & 4471.5 & 6.1438 & 3. 8982 & 2.2456 & 1991.2 & 1041.2 & 950.0 & .4930 \\
\hline & 6 & 4478.1 & -7.2 & 4470.9 & 3.8982 & 1.6695 & 2.2287 & 2006.1 & 1042.8 & 963.3 & .4999 \\
\hline & 7 & 1789.7 & 0.0 & 1789.7 & 1.6695 & .7827 & .8868 & 2018.1 & 1043.9 & 974.2 & .5055 \\
\hline \multirow[t]{8}{*}{ Aug. 6} & 1 & 9154.1 & 0.0 & 9154 & 40.8110 & 35.8648 & 4. 9462 & 1850.7 & 1013.4 & 837.3 & .4345 \\
\hline & 2 & 18356.7 & +3.1 & 18360 & 35.8648 & 26.1189 & 9.7459 & 1883.8 & 1020.2 & 863.6 & .4481 \\
\hline & 3 & 18325.1 & -1.4 & 18324 & 26.1189 & 16.6050 & 9.5139 & 1926.0 & 1028.4 & 897.6 & .4658 \\
\hline & 4 & 18313.1 & +1.2 & 18314 & 16.6045 & 7.3042 & 9.3003 & 1969.2 & 1035.9 & 933.3 & .4843 \\
\hline & 5 & 9159.1 & -3.1 & 9156 & 7.3037 & 2.7250 & 4.5787 & 1999.7 & 1041.1 & 958.6 & .4974 \\
\hline & 6 & 1836.4 & -3.4 & 1833.0 & 2.7236 & 1.8116 & .9119 & 2010.0 & 1043.1 & 966.9 & .5017 \\
\hline & 7 & 1835.8 & -2.5 & 1833.3 & 1.8116 & .9028 & .9088 & 2017.2 & 1043.8 & 973.4 & .5051 \\
\hline & 8 & 1146.6 & +1.2 & 1147.8 & .9028 & .3401 & .5627 & 2039.8 & 1044.3 & 995.5 & .5166 \\
\hline \multirow[t]{8}{*}{ Aug. 7} & 1 & 18288.0 & -3.3 & 18285 & 39.5670 & 29.7674 & 9.7996 & 1865.9 & 1016.9 & 849.0 & .4405 \\
\hline & 2 & 18297.4 & -5.3 & 18292 & 29.7674 & 20.1960 & 9.5714 & 1911.0 & 1025.4 & 885.6 & .4596 \\
\hline & 3 & 18276.0 & -8.5 & 18267 & 20.1960 & 10.8384 & 9.3576 & 1952.2 & 1033.2 & 919.0 & .4769 \\
\hline & 4 & 18280.0 & -4.6 & 18275 & 10.8360 & 1.6742 & 9.1618 & 1994.7 & 1040.3 & 954.4 & .4952 \\
\hline & 5 & 2287.6 & -1.4 & 2286.2 & 1.9562 & .8220 & 1.1342 & 2015.7 & 1042.3 & 973.4 & .5051 \\
\hline & 6 & 1141.9 & 0.0 & 1141.9 & .8220 & .2656 & .55635 & 2052.5 & 1044.4 & 1008.1 & .5231 \\
\hline & 7 & 454.2 & -1.4 & 452.8 & .2656 & .0727 & .19290 & 2347.3 & 1044.7 & 1302.6 & .6759 \\
\hline & 8 & 122.6 & -0.2 & 122.4 & .0733 & .0453 & .02795 & 4379.3 & 1044.7 & 3334.6 & 1.730 \\
\hline
\end{tabular}




\section{TABLE 9}

\section{Specific Heat of Ice}

Sample No. 4, Reduction of Results

\begin{tabular}{|c|c|c|c|c|c|c|c|c|c|}
\hline $\begin{array}{c}\text { Initial } \\
\text { tem- } \\
\text { pera- } \\
\text { ture } \\
\theta_{1}\end{array}$ & $\begin{array}{c}\text { Final } \\
\text { tempera- } \\
\text { ture } \\
\theta_{2}\end{array}$ & $\sqrt{\theta_{1} \theta_{2}}=\theta$ & $\frac{\theta_{1}+\theta_{2}}{2}=\theta^{\prime}$ & $\theta-\theta^{\prime}$ & $\mathbf{A}\left(\theta-\theta^{\prime}\right)$ & $\begin{array}{c}\text { Mean } \\
\text { specific } \\
\text { heat } \\
\theta_{1} \text { to } \theta_{2}= \\
\mathrm{s}_{\mathrm{m}}\end{array}$ & $\begin{array}{c}\text { Specific } \\
\text { heat } \\
\text { corrected } \\
\text { to } \theta \\
\mathbf{s}^{\text {tobs }}\end{array}$ & ${ }^{s} \theta_{\text {calc. }}$ & ${ }^{s_{\theta_{\text {obs }}-}}$ \\
\hline $\operatorname{deg} C$ & $\operatorname{deg} C$ & $\operatorname{deg} C$ & $\operatorname{deg} C$ & $\operatorname{deg} C$ & & $\frac{c a l_{20}}{\sigma \cdot d e \sigma}$ & & & \\
\hline-40.811 & -35.865 & -38.258 & -38.338 & 0.080 & 0.0001 & 0.4345 & 0.4346 & 0.43 .44 & +0.0002 \\
\hline 39.567 & 29.767 & 34.319 & 34.667 & .348 & .0006 & .4405 & .4411 & .4418 & -.0007 \\
\hline 35.865 & 26.119 & 30.607 & 30.992 & .385 & .0007 & .4481 & .4488 & .4487 & +.0001 \\
\hline 36.063 & 27.973 & 31.761 & 32.018 & .257 & .0005 & .4449 & .4454 & .4465 & -.0011 \\
\hline 27.973 & 20.045 & 23.680 & 24.009 & .329 & .0006 & .4593 & . 4599 & .4616 & -.0017 \\
\hline 29.767 & 20.196 & 24.519 & 24.982 & .463 & .0009 & .4596 & .4605 & .4600 & +.0005 \\
\hline 26.119 & 16.605 & 20.826 & 21.362 & .536 & .0010 & .4658 & .4668 & .4669 & -.0001 \\
\hline 20.196 & 10.834 & 14. 792 & 15.515 & .723 & .0013 & .4769 & .4782 & .4781 & +.0001 \\
\hline 19.857 & 10.665 & 14.552 & 15.261 & .709 & .0013 & .4766 & .4779 & .4786 & -.0007 \\
\hline 16.604 & 7.304 & 11.012 & 11.954 & .942 & .0018 & .4843 & .4861 & .4852 & +.0009 \\
\hline 10.665 & 6.144 & 8.095 & 8.404 & .309 & .0006 & .4890 & .4896 & .4907 & -.0011 \\
\hline 10.836 & 1.674 & 4.259 & 6.255 & 1.996 & .0037 & .4952 & . 4989 & .4980 & +.0009 \\
\hline 7.304 & 2.725 & 4.461 & 5.014 & .553 & .0010 & .4974 & .4984 & .4976 & +.0008 \\
\hline 6.144 & 3.898 & 4.894 & 5.021 & .127 & .0002 & .4930 & .4932 & .4968 & -.0036 \\
\hline 3.898 & 1.670 & 2.552 & 2.784 & .232 & .0004 & .4999 & .5003 & .5015 & -.0012 \\
\hline 2.724 & 1.812 & 2.222 & 2.268 & .046 & .0001 & .5017 & .5018 & .5024 & -.0006 \\
\hline 1.956 & .822 & 1.268 & 1.389 & .121 & .0002 & .5051 & .5053 & .5058 & -.0005 \\
\hline 1.812 & .903 & 1.279 & 1.358 & .079 & .0001 & .5051 & .5052 & .5057 & -.0005 \\
\hline 1.669 & .783 & 1.143 & 1.226 & .083 & .0002 & .5055 & .5057 & .5066 & -.0009 \\
\hline .903 & .340 & .554 & .622 & .068 & .0001 & .5166 & .5167 & .5177 & -.0010 \\
\hline .822 & .266 & .468 & .544 & .076 & .0001 & .5231 & .5232 & .5234 & -.0002 \\
\hline .266 & .073 & .139 & .170 & .031 & .0001 & .6759 & .6760 & .7116 & -.0356 \\
\hline .073 & $.045_{z}$ & $.057_{8}$ & $.059_{8}$ & $.001_{7}$ & .0000 & 1.730 & 1.730 & 1.7326 & -.0026 \\
\hline
\end{tabular}


A preliminary examination of these results was made by plotting the observed mean specific heats with reference to the average temperatures, $\frac{I}{2}\left(\theta_{1}+\theta_{2}\right)$ taken as abscissas. This examination tion indicated that the curves of specific heat were asymptotic to a straight line, the departure from which was apparent only above $-8^{\circ}$ for samples I, 2 , and 3 , and above $-2^{\circ}$ for sample 4 . Qualitatively, Smith's ${ }^{18}$ observation that the specific heat of ice tends toward constancy as the impurities in the ice are reduced appeared to be corroborated.

The degree of purity of the several samples was not known. Conductivity tests did not indicate great difference in purity, but this fact might be accounted for by the difficulty in transferring a sample from the container to the conductivity apparatus without contaminating the specimen. It was supposed from consideration of the refinement in method of preparing the samples that progress toward purity had been achieved, at least in sample 4 .

Before proceeding further with the analysis of the experimental data it is necessary to consider the relation between the apparent specific heat of ice and the presence of dissolved impurities.

Relation Between Apparent Specific Heat of Ice and Dissolved Impurities.-Consideration of the form of specific heat curves referred to above appeared to indicate that over the range of temperature employed the specific heat of pure ice bears a linear relation to the temperature, and that the departure from this linear relation is attributable to the fusion of a portion of the sample due to contained impurity. As a basis for the analysis of the results this is assumed.

From experiment it is known that for dilute solutions of substances which lower the freezing point the lowering is very nearly proportional to the concentration. Since the samples of water used here were extremely dilute solutions of the impurities, it is assumed that over the range of temperature within which the impurities produce any significant effect upon the apparent specific heat, this proportionality of the concentration to the lowering of the freezing point holds true. 
Consider a specimen of ice containing a small amount of impurity which lowers the initial freezing point from that of pure ice. Let

$l=$ the lowering of the initial freezing point

$K=$ the concentration of impurity when sample is all melted

$\theta=$ any temperature below $l$

$m=$ amount of unfrozen solution per gram of entire specimen at temperature $\theta$

$L=$ latent heat of fusion of ice

$s=$ true specific heat of pure ice at temperature $\theta$

$S=$ apparent specific heat of ice specimen at temperature $\theta$

$H_{f}=$ total heat of fusion of the portion unfrozen at temperature $\theta$, per gram of the specimen; $H_{f}=m L$.

Since the total amount of impurity is fixed, the concentration of the unfrozen portion of the sample is equal to $\frac{K}{m}$ Hence

$$
\frac{\theta}{l}=\frac{K}{m K} \text { or } m=\frac{l}{\theta}
$$

By definition

substituting for $m$,

$$
H_{f}=m L
$$

$$
H_{f}=\frac{l L}{\theta}
$$

differentiating with respect to $\theta$

$$
\frac{d H_{f}}{d \theta}=-\frac{l L}{\theta^{2}}
$$

The apparent specific heat of the specimen may be separated into four parts, namely, that due to the specific heat of the ice, that due to the specific heat of the water present, that due to fusion of a part of the ice, and that due to dilution of the solution present. Let these be designated, respectively,

$$
\frac{d H_{i}}{d \theta}, \quad \frac{d H_{w}}{d \theta}, \quad \frac{d H_{f}}{d \theta}, \frac{d H_{s}}{d \theta} .
$$


Since the amount of ice at temperature $\theta$ is $\mathrm{I}-m$ per gram of specimen,

$$
\frac{d H_{i}}{d \theta}=(I-m) s,
$$

calling $s_{w}$ the specific heat of water

$$
\frac{d H_{w}}{d \theta}=s_{w} m \text {. }
$$

The expression for apparent specific heat of ice may now be written

$$
S=s(\mathrm{I}-m)+s_{w} m-L \frac{l}{\theta^{2}}+\frac{d H_{s}}{d \theta},
$$

or since $m=\frac{l}{\theta}$,

$$
S=s+\left(s_{w}-s\right) \frac{l}{\theta}-L \frac{l}{\theta^{2}}+\frac{d H_{s}}{d \theta} .
$$

For the dilute solutions here considered the last term may be entirely neglected. Since $s_{w}-s$ is small compared to $L$ the constant value $\mathrm{I} . \mathrm{OI}-0.5 \mathrm{O}=0.5 \mathrm{I}$ is taken for this term. Taking 79.75 for $L$, the equation becomes

$$
S=s+0.5 \times \frac{l}{\theta}-79.75 \frac{l}{\theta^{2}} .
$$

Since by assumption $s=B+A \theta$, this equation becomes

$$
S=B+A \theta+0.5 \mathrm{I} \frac{l}{\theta}-79.75 \frac{l}{\theta^{2}} .
$$

In order to determine whether the experimental data satisfies equation 3 it is necessary to refer the observed mean specific heats to definite temperatures instead of the temperature intervals in terms of which they are derived.

The term $0.5 \mathrm{I} \frac{l}{\theta}$ may be neglected, since for small values of $\theta$ it is small compared with $79.75 \frac{l}{\theta^{2}}$ and for other values of $\theta$ it is small compared to $S$.

Equation 3 then becomes

$$
S_{\theta}=B+A \theta-79.75 \frac{l}{\theta^{2}}
$$


Integrating between $\theta_{1}$ and $\theta_{2}$ gives the total heat for this temperature interval, which is written

$$
H_{2}-H_{1}=B\left(\theta_{2}-\theta_{1}\right)+\frac{A}{2}\left(\theta_{2}{ }^{2}-\theta_{1}{ }^{2}\right)+79.75\left(\frac{l}{\theta_{2}}-\frac{l}{\theta_{1}}\right),
$$

dividing by $\theta_{2}-\theta_{1}$ gives the mean specific heat

$$
\frac{H_{2}-H_{1}}{\theta_{2}-\theta_{1}}=S_{m}=B+A \frac{\theta_{2}+\theta_{1}}{2}-79.75 l \frac{\mathrm{I}}{\theta_{1} \theta_{2}} .
$$

If $\theta_{1} \theta_{2}=\theta^{2}$

but

$$
S_{m}=B+A \frac{\theta_{2}+\theta_{1}}{2}-79.75 l \frac{\mathrm{I}}{\theta^{2}},
$$

$$
S_{\theta}=B+A \theta-79.75 l \frac{\mathrm{I}}{\theta^{2}}
$$

and therefore

$$
S_{\theta}-S_{m}=A\left(\theta-\frac{\theta_{2}+\theta_{1}}{2}\right) \text {. }
$$

if $A$ is known the value of $S_{\theta}-S_{m}$ may be calculated from this equation. If this term is added as a correction to the observed values of $S_{m}$ and $\theta$ be chosen equal to $-\sqrt{\theta_{1} \theta_{2}}$, there is obtained a series of values of $S$ determined experimentally, referred to corresponding values of $\theta$ which may now be examined with respect to their agreement with equation 4 .

The value of $A$ used for this reduction was 0.00186 , obtained from the preliminary graph of the data.

In Tables $3,5,7$, and 9 are given the steps in reduction of the data, resulting in a series of values of $S_{\theta}$ given in column 8 referred to corresponding values of $\theta$ given in column 3. In column 9 are given values of $S$ calculated from equation 4 , using the values for $B, A$, and $l$ as follows:

$$
\begin{array}{lcc}
B=0.5057 & \text { Sample. } & l . \\
A=0.001863 & \mathrm{I} & -0.00125 \\
& 2 & -.00120 \\
& 3 & -.00095 \\
& 4 & -.00005
\end{array}
$$

The differences between the experimental and calculated values of $S$ are given in column ro headed $S_{\theta o b s}-S_{\theta c a l}$. 
Consideration of the sources of error which may affect the values of $S$ shows that $S_{\text {obs }}-S_{\text {cal }}$ is more affected by errors in temperature measurement the smaller the numerical value of $\theta$ or of $\theta_{2}-\theta_{1}$. Greater differences between the experimental and calculated values may therefore be expected at temperatures near zero than elsewhere. Making due allowance for this fact, examination of the values of $S_{\mathrm{obs}}-S_{\mathrm{cal}}$ shows that the agreement between experimental and calculated values is within the limits of experimental precision. In other words, the specific heat of ice samples numbers $\mathrm{I}, 2,3$, and 4 in the range of temperature from $-40^{\circ} \mathrm{C}$ to $-.05^{\circ} \mathrm{C}$ is represented within the limit of experimental error by the equation

$$
S_{\theta}=0.5057+0.001863 \theta-79.75 \frac{l}{\theta^{2}}
$$

where $l$ has the following values:

\begin{tabular}{|c|c|}
\hline sample. & $l$ \\
\hline I & -0.00125 \\
\hline 2 & -.00120 \\
\hline 3 & -.0009 \\
\hline 4 & . \\
\hline
\end{tabular}

Discussion of Results. - The results of the determinations of specific heat are graphically represented in Fig. 6. The curve of calculated values for sample No. 2 is omitted because it is scarcely distinguishable from that of sample No. I. The results in the range of temperature -10 to $0^{\circ} \mathrm{C}$ are shown in Fig. 7 plotted to a larger scale of temperature.

In arriving at the above results the assumption has been made that the measure of the departure of the specific heat of any specimen of impure ice from a linear function of the temperature can be expressed in terms of a constant representing the initial freezing point and depending upon the degree of purity.

The results upon four samples of ice all of high degree of purity, yet differing among themselves in purity, agree with this assumption, but it does not necessarily follow that the assumption is substantially correct. It is quite possible that the relation of 
74

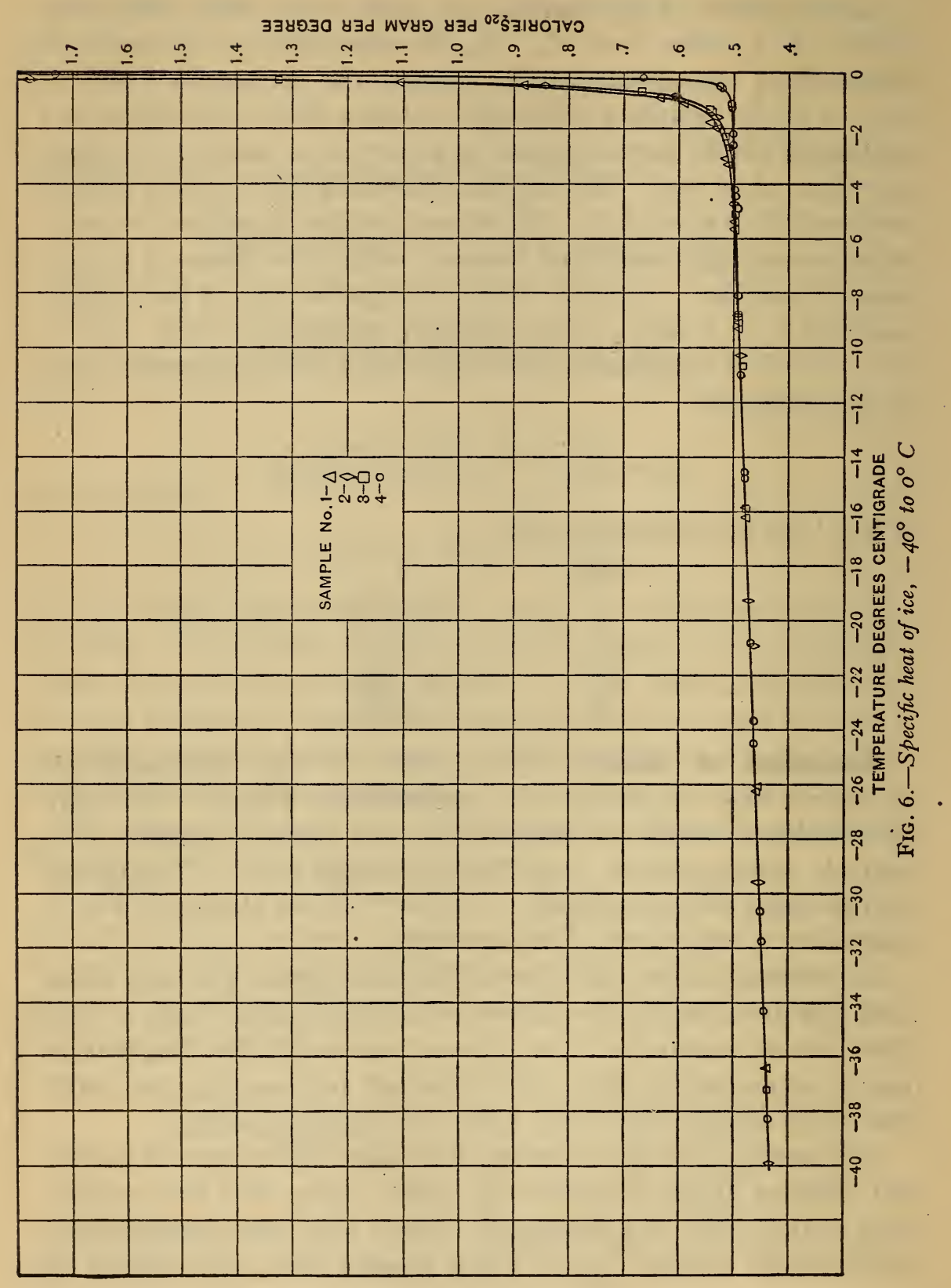




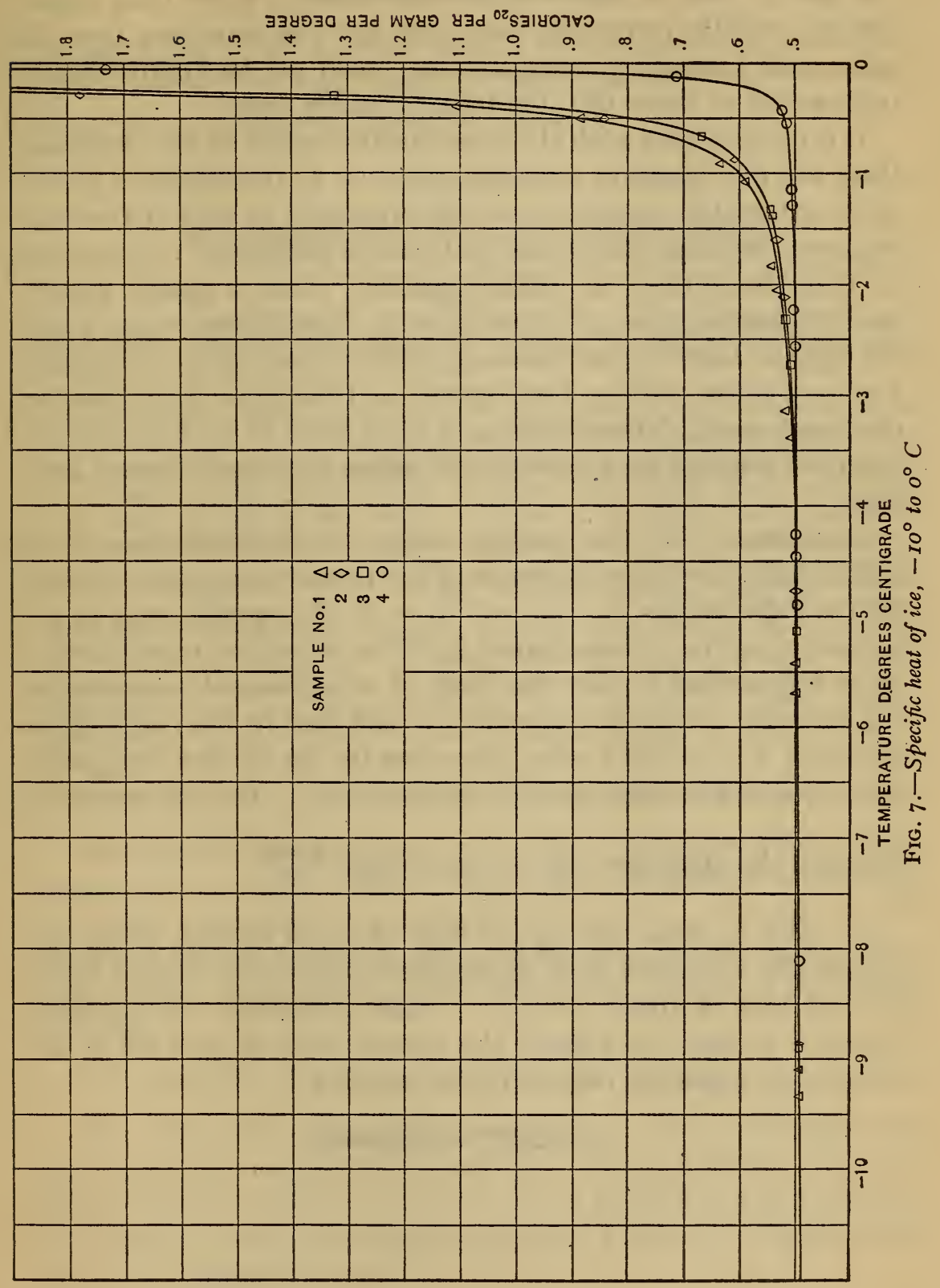


the specific heat of pure ice to temperature is other than linear, perhaps rapidly increasing near zero and the departure from its value with increasing contamination could yet be approximately represented in terms of $l$, the initial freezing point.

It is obvious that with the experimental means at our command there are two ultimate limitations, one as to the degree of purity of ice attainable, another as to the proximity to zero of the temperatures between which total heats can be measured. On account of these limitations no rigid conclusion from a purely experimental standpoint can be drawn as to the ultimate value which the specific heat of pure ice may attain in the range of temperature just before melting takes place; and therefore the separation of experimental determinations of total heat of ice into the elements of sensible heat and heat of fusion is to some extent arbitrary.

Conclusion.-In the present series of determinations it is found that over the greater part of the temperature range covered by the experiments, i. e., $-40^{\circ}$ to $-2^{\circ}$, the specific heat in $20^{\circ}$ calories at a given temperature $\theta$, of the purest ice experimented on is represented within the limit of experimental accuracy by the equation $s=0.5057+0.001863 \theta$, and that in the range closer to zero, i. e., $-2^{\circ}$ to -0.05 , the purer the ice the less the specific heat exceeds the value given by this equation. For the purest ice

obtained the departure was not more than $\frac{0.004}{\theta^{2}}$.

In order to state the specific heat of ice in definite terms and permit the deduction from experimental data of a definite figure for the heat of fusion of ice, it seems justifiable, for technical purposes at least, to express the specific heat of pure ice in $20^{\circ}$ calories per gram per degree by the equation

$$
s=0.5057+0.001863 \theta
$$




\section{HEAT OF FUSION OF ICE}

Upon three of the samples used in the specific heat determinations observations were made to determine the heat of fusion. The data and results are given in Table ro.

TABLE 10

Heat of Fusion of Ice-Results of Present Investigation

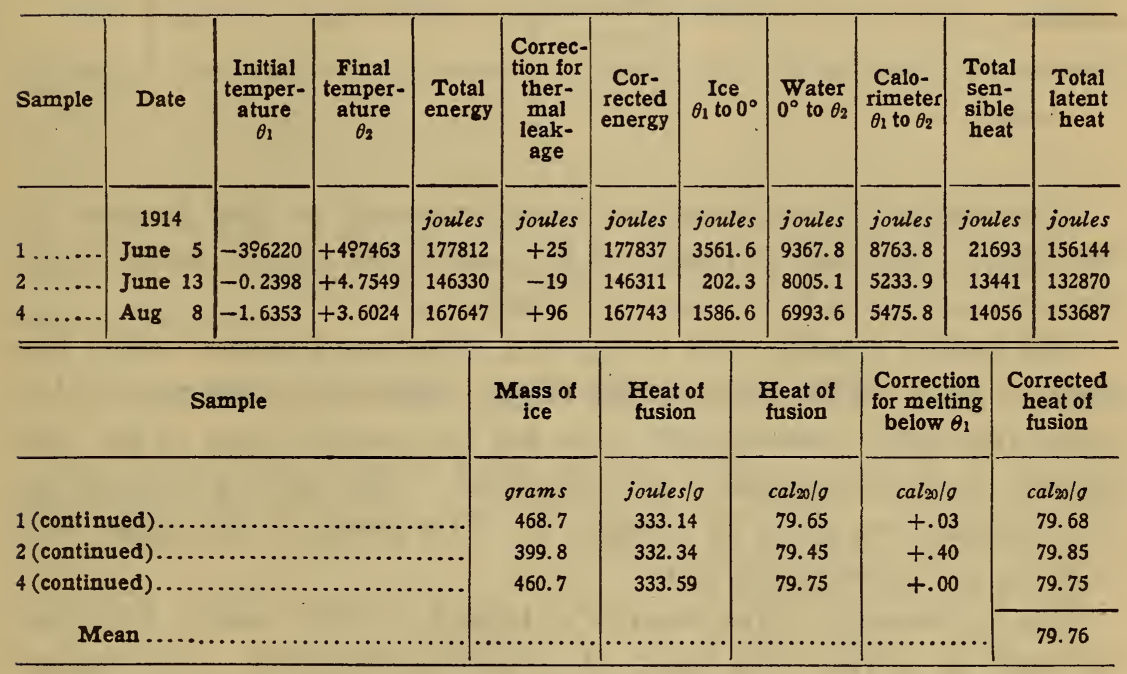

Since partial fusion of the sample, due to presence of impurities, takes place at temperatures below zero, as pointed out in the preceding discussion, it is necessary to apply a correction to the observed heat of fusion for the heat involved in the fusion which has already taken place at the initial temperature of the determination.

This correction is given by equation (I). $H_{f}=\frac{l L}{\theta}$.

The values of $l$ have been given above. The corrections for previous fusion are given in next to the last column. The corrected values for heat of fusion of ice are given in the last column. The mean of the three samples gives for the heat of fusion of ice $79.7620^{\circ}$ calories per gram.

$$
6844^{\circ}-15-6
$$


TABLE 11

Heat of Fusion of Ice-Results of Previous Determinations

\begin{tabular}{|c|c|c|c|c|c|c|}
\hline Method & Sampies & $\begin{array}{c}\text { Kind of } \\
\text { ice }\end{array}$ & $\begin{array}{c}\text { Initial } \\
\text { tempera- } \\
\text { ture of lce }\end{array}$ & $\begin{array}{l}\text { Heat of } \\
\text { fusion }\end{array}$ & $\begin{array}{l}\text { Corrected } \\
\text { heat of } \\
\text { fusion }\end{array}$ & $\begin{array}{l}\text { Corrected } \\
\text { heat of } \\
\text { fusion }\end{array}$ \\
\hline & & & $\operatorname{deg} C$ & $c a l_{15} / g$ & $c a l_{15} / g$ & cal $_{20} / \mathrm{g}$ \\
\hline Electrical.. & 13 & $\left\{\begin{array}{l}\text { Plate........ } \\
\text { Can..... }\end{array}\right.$ & -0.72 & 79.65 & 79.66 & 79.74 \\
\hline Mirtures.. & 8 & $\left\{\begin{array}{l}\text { Natural .. } \\
\text { Can...... }\end{array}\right.$ & -.72 & 79.61 & 79.62 & 79. 70 \\
\hline Electrical.... & 12 & Can...... & -3.78 & 79.65 & 79.70 & 79.78 \\
\hline Mean. & & & & & & 79.74 \\
\hline
\end{tabular}

The results of the previous investigation ${ }^{10}$ at the Bureau to determine the heat of fusion of ice, using the stirred water calorimeter, are given in column 5 of Table $\mathrm{I}$.

The earlier results were computed using an assumed value for specific heat of ice $=0.5^{2} \mathrm{cal} / \mathrm{g} \bullet \mathrm{deg}$. Correcting the results by using the newly determined value for the specific heat of ice, the figures given in column 6 are obtained. The results reduced to $20^{\circ}$ calories are given in column 7 . The mean of the three sets is $79.7420^{\circ}$ calories per gram.

The agreement of the results obtained by the widely different methods is within the limit of experimental error. The mean result of the two investigations is $79.7520^{\circ}$ calories per gram mass.

\section{SUMMARY}

By means of a calorimeter of the aneroid type-that is, employing the thermal conductivity of copper instead of the convectivity of a stirred liquid to distribute heat supplied electrically-the specific heat and heat of fusion of ice were determined.

The specific heat was determined upon four samples of ice, all of a high but yet of different degrees of purity.

A variation in the specific heat of ice is found which depends upon the degree of purity.

It is found that at a given temperature $\theta$, between $-40^{\circ}$ and $-2^{\circ}$, for the purest ice experimented on, the specific heat in $20^{\circ}$ 
calories per gram per degree is represented within the limit of experimental accuracy by the equation

$$
s=0.5057+0.001863 \theta
$$

and that from $-2^{\circ}$ to $-0^{\circ} .05$ the specific heat does not exceed the value given by the above equation by more than $\frac{0.004}{\theta^{2}}$.

The specific heat of impure ice at any temperature $\theta$ above $-40^{\circ}$ is greater than that of pure ice by $\frac{l L}{\theta^{2}}$ where $L$ is the heat of fusion and $l$ the initial freezing point.

The value found for the heat of fusion of ice is $79.7620^{\circ}$ calories per gram, which is within $\mathrm{I} / 4000$ of the value previously determined at the Bureau by a different method employing a stirred water calorimeter.

\section{TABLE OF TOTAL HEAT OF ICE AND WATER}

For the convenience of those accustomed to the use of total heats expressed in terms of British thermal units ${ }^{20}$ Table 12 has been prepared, giving in Btu per pound (weighed in air) the difference in total heat per pound, $H_{32}-H_{t}$, between ice at $t^{\circ} \mathrm{F}$ and ice at $32^{\circ} \mathrm{F} ; h_{32}-H_{t}$, between ice at $t^{\circ} \mathrm{F}$ and water at $32^{\circ} \mathrm{F}$; $h_{t^{\prime}}-h_{32}$, between water at $32^{\circ} \mathrm{F}$ and at $t^{\prime \circ} \mathrm{F}$.

If the specific heat $s$ of ice in $\mathrm{cal}_{20} / \mathrm{g} \cdot \operatorname{deg} \mathrm{C}$ at the temperature $\theta$ is expressed by the equation

$$
s=0.5057+0.001863 \theta,
$$

and the relation between units be taken as

$$
\text { I Btu/lb } \bullet \operatorname{deg} \mathrm{F}=\mathrm{I} .00 \mathrm{I} \mathrm{cal}_{20} / \mathrm{g} \bullet \operatorname{deg} \mathrm{C} \text {, }
$$

the specific heat $s^{\prime}$ of ice in $\mathrm{Btu} / \mathrm{lb} \bullet \operatorname{deg} \mathrm{F}$ at the temperature $t$ is given by the equation

$$
s^{\prime}=0.5052+0.001861(t-32) .
$$

${ }^{20}$ The British thermal unit used here is defined as the quantity of heat required to raise the temperature of I pound of water (weighed in air) $I^{\circ}$ Fahrenheit at $60^{\circ} \mathrm{F}$. 
TABLE 12

Table of Total Heat of Ice and Water

\begin{tabular}{|c|c|c|c|c|}
\hline \multirow{2}{*}{$\begin{array}{c}\text { Temperature } \\
\text { of ice } \\
t \\
\text { deg. } F\end{array}$} & \multicolumn{2}{|c|}{$\begin{array}{l}\text { Difference in total heat per pound from } \\
\text { ice at } t^{\circ} \text { to }\end{array}$} & \multirow{2}{*}{$\begin{array}{c}\text { Temperature } \\
\text { of water } \\
t^{1}\end{array}$} & \multirow{2}{*}{$\begin{array}{c}\text { Difference in total } \\
\text { heat per pound } \\
\text { from water at } 32^{\circ} \\
\text { to water at th } \\
h_{t}-h_{32}\end{array}$} \\
\hline & $\begin{array}{l}\text { Ice at } 32^{\circ} \\
\mathrm{H}_{32}-\mathrm{H}_{\mathrm{t}}\end{array}$ & $\begin{array}{c}\text { Water at } 32^{\circ} \\
\mathbf{h}_{32}-\mathbf{H}_{\mathbf{t}}\end{array}$ & & \\
\hline & $B t u / l b$ & $B t u / l b$ & $\operatorname{deg} . F$ & Btu/lb \\
\hline-20 & 23.8 & 167.2 & $+32^{\circ}$ & 0.0 \\
\hline-18 & 22.9 & 166.3 & 34 & 2.0 \\
\hline-16 & 22.1 & 165.5 & 36 & 4.0 \\
\hline-14 & 21.3 & 164.7 & 38 & 6.0 \\
\hline-12 & 20.4 & 163.8 & 40 & 8.1 \\
\hline-10 & 19.6 & 163.0 & 42 & 10.1 \\
\hline-8 & 18.7 & 162.1 & 44 & 12.1 \\
\hline-6 & 17.9 & 161.3 & 46 & 14.1 \\
\hline-4 & 17.0 & 160.4 & 48 & 16.1 \\
\hline-2 & 16.1 & 159.5 & 50 & 18.1 \\
\hline 0 & 15.2 & 158.6 & 52 & 20.1 \\
\hline+2 & 14.3 & 157.7 & 54 & 22.1 \\
\hline 4 & 13.4 & 156.8 & 56 & 24.1 \\
\hline 6 & 12.5 & 155.9 & 58 & 26.1 \\
\hline 8 & 11.6 & 155.0 & 60 & 28.1 \\
\hline 10 & 10.7 & 154.1 & 62 & 30.1 \\
\hline 12 & 9.7 & 153.1 & 64 & 32.1 \\
\hline 14 & 8.8 & 152.2 & 66 & 34.1 \\
\hline 16 & 7.8 & 151.2 & 68 & 36.1 \\
\hline 18 & 6.9 & 150.3 & 70 & 38.1 \\
\hline 20 & 5.9 & 149. 3 & 72 & 40.1 \\
\hline 22 & 5.0 & 148.4 & 74 & 42.1 \\
\hline 24 & 4.0 & 147.4 & 76 & 44.1 \\
\hline 26 & 3.0 & 146.4 & 78 & 46.1 \\
\hline 28 & 2.0 & 145.4 & 80 & 48.1 \\
\hline 30 & 1.0 & 144.4 & 82 & 50.1 \\
\hline \multirow[t]{6}{*}{32} & 0.0 & 143.4 & 84 & 52.1 \\
\hline & & & 86 & 54.1 \\
\hline & & & 88 & 56.1 \\
\hline & & 71 & 90 & 58.0 \\
\hline & & & 95 & 63.0 \\
\hline & & & 100 & 68.0 \\
\hline
\end{tabular}


The difference in total heat between ice at temperatures $t$ and 32 is given by the equation

$$
H_{32}-H_{i}=\int_{t}^{32} s^{\prime} d t=-0.505^{2}(t-32)-0.00093(t-32)^{2}
$$

If the heat of fusion of ice is taken as $79.75 \mathrm{cal}_{20} / g$ and the relation between units be taken as

$$
\text { I } \mathrm{Btu} / \mathrm{lb}=0.556 \mathrm{cal}_{20} / g
$$

the heat of fusion of ice is

$$
\text { I43.4 Btu/lb }
$$

EXAMPLE.-Required the number of Btu per pound required to change ice at $8^{\circ} \mathrm{F}$ into water at $68^{\circ} \mathrm{F}$ :

Column 3, opposite $8^{\circ}, h_{32}-H_{8}=155.0$

Column 5 , opposite $68^{\circ}, h_{68}-h_{32}=36.1$

$$
\text { adding } \quad h_{68}-H_{8}=\text { I9I.I }
$$

I9I.I is the number of Btu per pound required.

WASHINGTON, D. C., February 23, I9I5. 